\title{
Computations of Viking Lander Capsule Hypersonic Aerodynamics with Comparisons to Ground and Flight Data
}

\author{
Karl T. Edquist ${ }^{\dagger}$ \\ NASA Langley Research Center, Hampton, Virginia, 23681
}

\begin{abstract}
Comparisons are made between the LAURA Navier-Stokes code and Viking Lander Capsule hypersonic aerodynamics data from ground and flight measurements. Wind tunnel data are available for a 3.48 percent scale model at Mach 6 and a 2.75 percent scale model at Mach 10.35, both under perfect gas air conditions. Viking Lander 1 aerodynamics flight data also exist from on-board instrumentation for velocities between 2900 and $4400 \mathrm{~m} / \mathrm{sec}$ (Mach 14 to 23.3). LAURA flowfield solutions are obtained for the geometry as tested or flown, including sting effects at tunnel conditions and finite-rate chemistry effects in flight. Using the flight vehicle center-of-gravity location (trim angle $\approx \mathbf{- 1 1 . 1} \mathbf{~ d e g}$ ), the computed trim angle at tunnel conditions is within 0.31 degrees of the angle derived from Mach 6 data and 0.13 degrees from the Mach 10.35 trim angle. LAURA Mach 6 trim lift and drag force coefficients are within 2 percent of measured data, and computed trim lift-to-drag ratio is within 4 percent of the data. Computed trim lift and drag force coefficients at Mach 10.35 are within 5 percent and 3 percent, respectively, of wind tunnel data. Computed trim lift-todrag ratio is within 2 percent of the Mach 10.35 data. Using the nominal density profile and center-of-gravity location, LAURA trim angle at flight conditions is within 0.5 degrees of the total angle measured from on-board instrumentation. LAURA trim lift and drag force coefficients at flight conditions are within 7 and 5 percent, respectively, of the flight data. Computed trim lift-to-drag ratio is within 4 percent of the data. Computed aerodynamics sensitivities to center-of-gravity location, atmospheric density, and grid refinement are generally small. The results will enable a better estimate of aerodynamics uncertainties for future Mars entry vehicles where non-zero angle-of-attack is required.
\end{abstract}

\section{Nomenclature}

A $\quad$ acceleration $\left(\mathrm{m} / \mathrm{sec}^{2}\right)$

ARC Ames Research Center

a speed of sound $(\mathrm{m} / \mathrm{sec})$

CG center of gravity

$\mathrm{C}_{\mathrm{A}} \quad$ axial force coefficient, $\mathrm{F}_{\mathrm{A}} / \mathrm{q}_{\infty} \mathrm{S}_{\text {ref }}$

$\mathrm{C}_{\mathrm{D}} \quad$ drag force coefficient, $\mathrm{F}_{\mathrm{D}} / \mathrm{q}_{\infty} \mathrm{S}_{\mathrm{ref}}$

$\mathrm{C}_{\mathrm{L}} \quad$ lift force coefficient, $\mathrm{F}_{\mathrm{L}} / \mathrm{q}_{\infty} \mathrm{S}_{\mathrm{ref}}$

$\mathrm{C}_{\mathrm{N}} \quad$ normal force coefficient, $\mathrm{F}_{\mathrm{N}} / \mathrm{q}_{\infty} \mathrm{S}_{\mathrm{ref}}$

$\mathrm{C}_{\mathrm{m}} \quad$ pitching moment coefficient, $\mathrm{M} / \mathrm{q}_{\infty} \mathrm{S}_{\mathrm{ref}} \mathrm{D}$

$\mathrm{C}_{\mathrm{m}_{\alpha}} \quad$ static pitching moment stability, $\partial \mathrm{C}_{\mathrm{m}} / \partial \alpha\left(\mathrm{deg}^{-1}\right)$

$\mathrm{C}_{\mathrm{p}} \quad$ pressure coefficient, $\left(\mathrm{p}-\mathrm{p}_{\infty}\right) / \mathrm{q}_{\infty}$

$\mathrm{C}_{\mathrm{p}, \mathrm{stag}} \quad$ hypersonic stagnation pressure coefficient, $\mathrm{p}_{\text {stag }} / \mathrm{q}_{\infty}$

EDL Entry, Descent, and Landing

L/D lift-to-drag ratio

LaRC Langley Research Center

MER Mars Exploration Rovers

MPF Mars Pathfinder

MSL Mars Science Laboratory

$\bar{\dagger}$ Aerospace Engineer, Exploration Systems Engineering Branch, Mail Stop 489, AIAA Senior Member. 


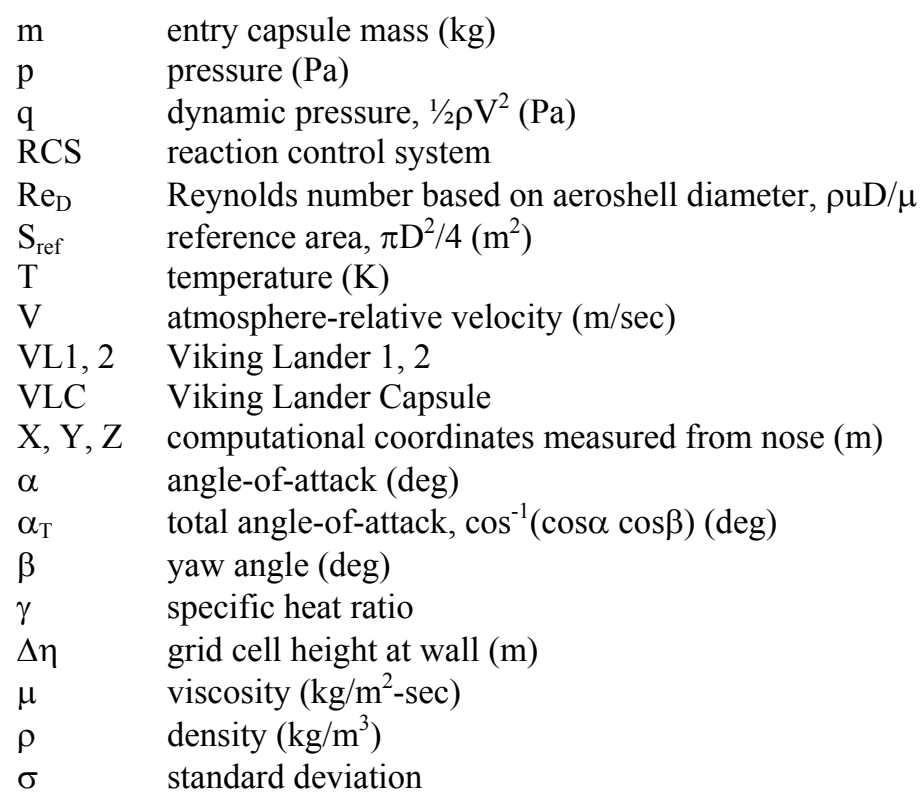

\section{Subscripts}

$\begin{array}{ll}\text { cg } & \text { center-of-gravity } \\ \text { ref } & \text { moment reference point } \\ \text { stag } & \text { stagnation condition } \\ \text { w } & \text { wall condition } \\ \infty & \text { freestream condition }\end{array}$

\section{Introduction}

$\mathrm{T}$ he Viking Lander 1 and 2 (VL1 and VL2) capsules were the first, and still the only, Mars atmospheric entry vehicles with a designed non-zero trim angle-of-attack. Both vehicles were built to fly at a trim angle of $-11.1 \mathrm{deg}$ and a lift-to-drag ratio (L/D) of $0.18^{1}$. In the absence of modern computational fluid dynamics (CFD) methods, preflight estimates for the Viking aerodynamics were based on wind tunnel data in air ground facilities, with corrections for the effects of flying in a $\mathrm{CO}_{2}$ atmosphere. The only successful entry vehicles since Viking, Mars Pathfinder (MPF) and the Mars Exploration Rovers (MER), were designed to fly with zero angle-of-attack. The aerodynamics for MPF and MER were based almost completely on computational fluid dynamics flowfield solutions $^{2-4}$. Consequently, no ground-based aerodynamics test programs were conducted for those vehicles, other than ballistic range testing for dynamic stability characterization ${ }^{5}$. Both MPF and MER were spin-stabilized, so the aerodynamics prediction at zero $\mathrm{L} / \mathrm{D}$ was not as critical as it would be for an entry that depended on lift for target accuracy and altitude performance. CFD methods were used to predict static instabilities $\left(\mathrm{C}_{\mathrm{m}_{\alpha}}>0\right)$ for MPF and MER that were observed in flight, which provides some validation of computational tools for hypersonic aerodynamics prediction ${ }^{3}$.

As entry system mass and performance requirements increase for future Mars missions, the need for lift requires flying at a non-zero angle-of-attack once again. The lift is used by the entry guidance algorithm to reduce landing ellipse errors caused by uncertainties in navigation, aerodynamics, and atmospheric properties. For example, a hypersonic trim $\alpha$ of $16 \mathrm{deg}(\mathrm{L} / \mathrm{D}=0.24)$ is being considered for the Mars Science Laboratory $(\mathrm{MSL})^{6}$. The landed ellipse is expected to be on the order of $10 \mathrm{~km}$, compared to $100 \mathrm{~km}$ for the MPF and MER ballistic entries. The continued use of CFD methods for supersonic and hypersonic aerodynamics prediction necessitates validation of those methods for non-zero angle-of-attack flight. To the author's knowledge, limited published attempts have been made to rigorously validate computational tools against available hypersonic aerodynamics data for 70-degree sphere-cone geometries, especially at non-zero angle-of-attack. Some computations have been compared to Viking ballistic range drag coefficient ${ }^{3}$, but a wealth of Viking wind tunnel and flight data still exists for additional 
comparisons. The objective of this paper is to compare CFD methods to Viking hypersonic ground and flight aerodynamics data, focusing on higher angle-of-attack results $(\geq 11 \mathrm{deg})$. CFD methods show good agreement with supersonic MSL data for Mach numbers between 2.3 and $4.5^{7-8}$.

Analysis of Entry, Descent, and Landing (EDL) systems requires many engineering models that represent the behavior of the system as it descends through the atmosphere. Examples of required models are guidance, propulsion, atmosphere, and aerodynamic. Monte-Carlo analyses of the EDL system allows engineers to consider a wide range of entry scenarios and the impact of model uncertainties on system performance ${ }^{6}$. Proper estimation of the entry vehicle aerodynamic coefficients and their uncertainties is critical for a complete understanding of the EDL system and its robustness to anomalous conditions. Comparison of computational tools using available data is an important step in estimating aerodynamics uncertainties for future Mars entry vehicles. The potential benefit is that with reduced aerodynamic uncertainties, the entry system can be designed to handle a smaller range of entry conditions without increased risk.

\section{Analysis}

Figure 1 shows the full-scale VLC geometry. The Viking entries set the precedent for using a blunted 70degree sphere-cone forebody as the primary decelerator. The forebody shape was chosen because it resulted in a small ballistic coefficient $\left(\mathrm{m} / \mathrm{C}_{\mathrm{D}} \mathrm{S}_{\mathrm{ref}}\right)$ and sufficient stability that required minimal control system usage ${ }^{9}$. The same forebody shape has been used for all subsequent Mars entry capsules. The entry capsule was flown with negative trim angle (positive lift) to help dissipate the entry system kinetic energy and reach the desired parachute deployment conditions. In order to achieve the desired trim angle, the capsule's CG was placed at an axial distance of 0.2209 diameters behind the nose and a radial distance of 0.0133 diameters from the axis of symmetry 9

Aerodynamic lift is derived from the axial force and is in the direction opposite of the angle-of-attack $(\mathrm{L} / \mathrm{D}<0$ for $\alpha>0$, Fig. 2). Force coefficients in the body-reference frame $\left(\mathrm{C}_{\mathrm{A}}, \mathrm{C}_{\mathrm{N}}\right)$ can be translated to the velocity vector frame $\left(C_{L}, C_{D}\right)$ using the following equations:

$$
\begin{aligned}
& C_{L}=-C_{A} \sin \alpha+C_{N} \cos \alpha \\
& C_{D}=C_{A} \cos \alpha+C_{N} \sin \alpha
\end{aligned}
$$

For blunt bodies $\left(C_{A} \gg C_{N}\right)$ at small angles, both $C_{L}$ and $C_{D}$ are dominated by $C_{A}$. The pitching moment coefficient

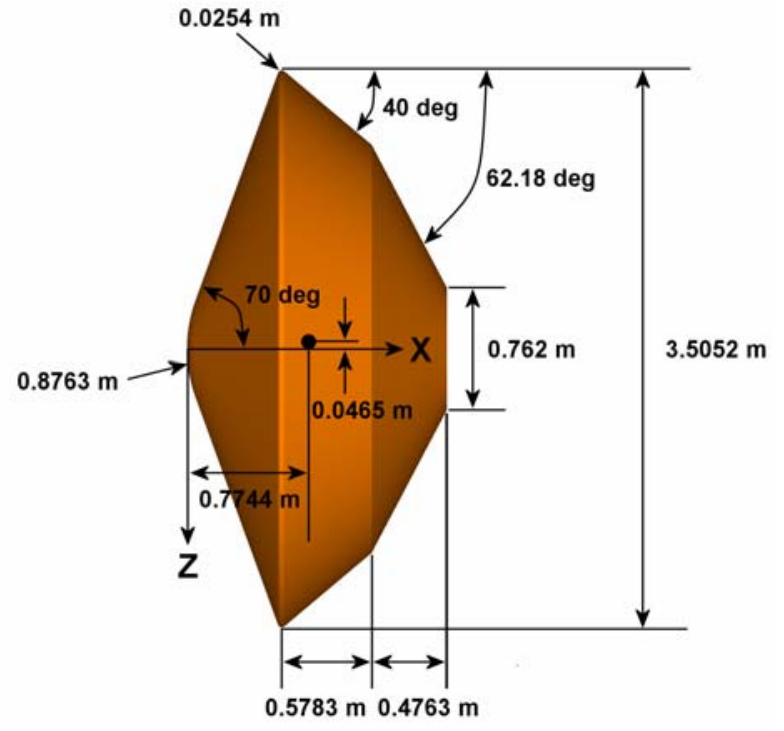

Figure 1. Full Scale Viking Lander Capsule (Ref. 1)

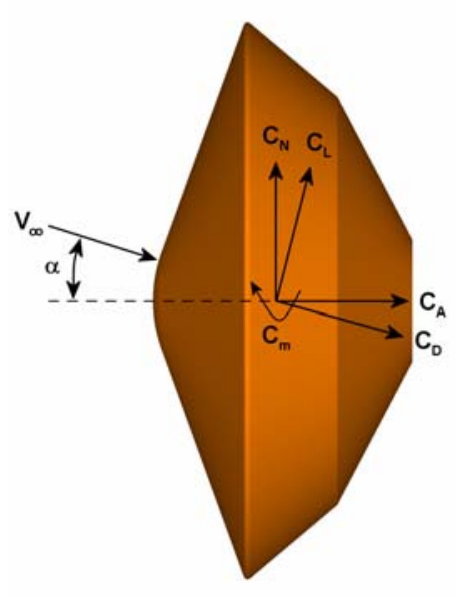

Figure 2. Static Aerodynamic Coefficients 
$\left(\mathrm{C}_{\mathrm{m}}\right)$ can be translated from the reference point to the center-of-gravity $(\mathrm{CG})$ location using the following equation:

$$
C_{m, c g}=C_{m, r e f}+C_{N}\left(\frac{X_{c g}-X_{r e f}}{D}\right)-C_{A}\left(\frac{Z_{c g}-Z_{r e f}}{D}\right)
$$

Equation 3 can be used to determine the required $C G$ location for a desired trim angle $\left(C_{m, c g}=0\right)$ and $L / D$. The slope of $\mathrm{C}_{\mathrm{m}, \mathrm{cg}}$ with respect to angle-of-attack $\left(\mathrm{C}_{\mathrm{m}_{\alpha}}\right)$ is important because it indicates the static stability of the trim conditions. The more negative is $\mathrm{C}_{\mathrm{m}_{\alpha}}$, the more stable is the vehicle.

\section{A. VLC Ground Test Data}

Given that the Viking landers were the first of their kind, an extensive test program was executed to determine the Viking Lander Capsule (VLC) static aerodynamic coefficients as a function of angle-of-attack and Mach number-14. The aerodynamic data were used for pre-flight trajectory analysis and post-flight reconstruction. The ground data were obtained primarily for sting-mounted models in air wind tunnels ${ }^{10}$. Other tests were executed to obtain transonic data for the entry aeroshell and lander/backshell configurations ${ }^{11-12}$. Limited data also exist for $\mathrm{CO}_{2}{ }^{13}$ and $\mathrm{CF}_{4}{ }^{14}$ test facilities to estimate the effects of the predominantly $\mathrm{CO}_{2}$ atmosphere at Mars. The $\mathrm{CF}_{4}$ facility provides a better approximation of the $\mathrm{CO}_{2}$ specific heat ratio $(\gamma)$ and shock density ratio than does air. The preflight estimate was that the $\mathrm{CO}_{2}$ drag coefficient was $3 \%$ higher than for air ${ }^{9}$. Results in $\mathrm{CF}_{4}$ indicate that $\mathrm{L} / \mathrm{D}$ is insensitive to shock density ratio, but pitching moment is higher for a given $\alpha$ than for air $^{14}$. Ballistic range tests were also conducted to obtain pitch damping characteristics ${ }^{15}$.

Table 1 summarizes most of the available force and moment test data. The VLC aerodynamics database covered Mach numbers from 0.4 to 10.35 and angle-of-attack from 0 to 24 degrees ${ }^{9}$. The aerodynamics were considered to be independent of Reynolds number and independent of Mach number for Mach $>10.35$. Reference 9 contains wind tunnel data obtained in NASA Langley Research Center facilities from Mach 1.5 to Mach 10.35, all with air as the test gas. The Langley Unitary Plan Wind Tunnel was used to test between Mach 1.5 and 4.6. The 20-Inch Mach 6 Tunnel and 31-Inch Continuous Flow Hypersonic Tunnel were used to test at hypersonic Mach numbers. Scale models $(2.75 \%$ and $3.48 \%$ ) of the $3.5 \mathrm{~m}$ flight vehicle were tested with and without the backshell in the hypersonic air facilities. Free-flight tests were also conducted in two NASA Ames Research Center facilities, the Ames Pressurized Ballistic Range (PBR, air) and Ames Hypervelocity Free-Flight Aerodynamic Facility (HFAF, $\left.\mathrm{CO}_{2}\right)^{14}$. These tests focused on the dynamic stability characteristics of the Viking entry capsule.

Table 1. VLC Static Aerodynamics Test Data

\begin{tabular}{cccccccc}
\hline \hline Facility & Type & Gas & $\mathrm{M}_{\infty}$ & $\mathrm{Re}_{\mathrm{D}} \times 10^{-6}$ & Scale (\%) & $\alpha$ (deg) & Ref. \\
\hline LaRC 8-Foot Transonic & Tunnel & Air & 0.4 to 1.2 & 0.74 to 1.84 & 8 & -1 to 24 & 11,12 \\
\hline LaRC Unitary Plan & Tunnel & Air & 1.5 to 4.6 & 0.4 & 3.48 & -4 to 20 & 10 \\
\hline LaRC 20-Inch Mach 6 Air & Tunnel & Air & 6 & 1.24 to 2.84 & 3.48 & -3 to 20 & 10 \\
\hline LaRC 20-Inch Mach 6 CF 4 4 & Tunnel & $\mathrm{CF}_{4}$ & 6 & N/A & 2.90 & 0 to 16 & 14 \\
\hline LaRC Mach 8 & Tunnel & Air & 8 & N/A & 2.90 & 0 to 16 & 14 \\
\hline LaRC 31-Inch CFHT & Tunnel & Air & 10.35 & 0.32 & 2.75 & -6 to 25 & 10 \\
\hline ARC PBR & Range & Air & 2 & 0.6 & $0.291,0.579$ & N/A & 13 \\
\hline ARC HFAF & Range & $\mathrm{CO}_{2}$ & 11.3 & 0.89 & $0.291,0.579$ & N/A & 13 \\
\hline
\end{tabular}

This paper compares CFD aerodynamics to the Mach 6 and 10.35 data in air. Figure 3 shows VLC tunnel data for those Mach numbers ${ }^{9}$. Axial and drag force coefficients were measured to be slightly higher at Mach 10.35 (Fig. 3a). Otherwise, the aerodynamics are nearly identical. Both sets of data give a trim angle near $11.1 \mathrm{deg}$ using the flight vehicle CG location (Fig. 3e). The Mach 10.35 data shows a slightly more stable $\mathrm{C}_{\mathrm{m}_{\alpha}}$. The hypersonic design L/D of 0.18 at $11.1 \mathrm{deg}$ was shown to be independent of Mach number for perfect gas air (Fig. 3f). Post-flight analysis showed that the VL1 trim angle, $\mathrm{L} / \mathrm{D}$, and $\mathrm{C}_{\mathrm{A}}$ were higher than predicted ${ }^{1}$. The underprediction of $\mathrm{C}_{\mathrm{A}}$ was attributed to $\mathrm{CO}_{2}$ effects, while the misprediction of trim angle was considered to be caused by asymmetry effects. 


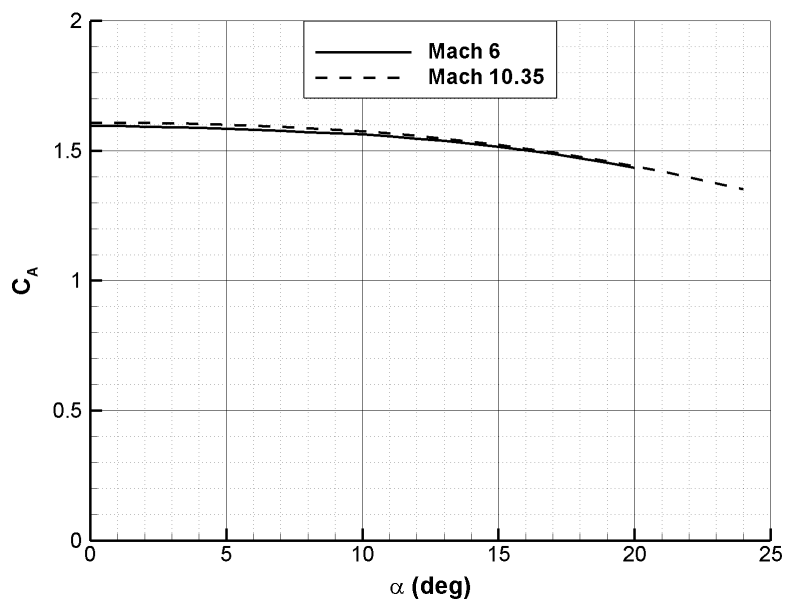

a. Axial Force Coefficient

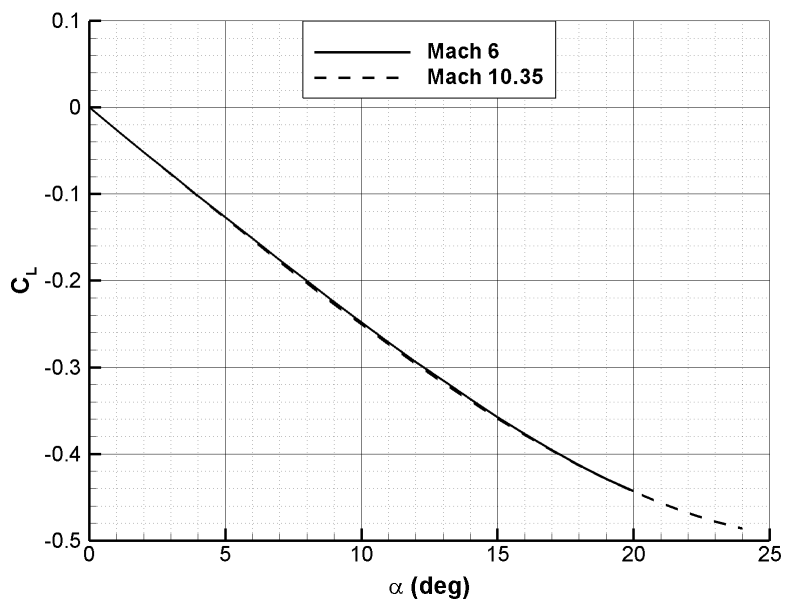

c. Lift Force Coefficient

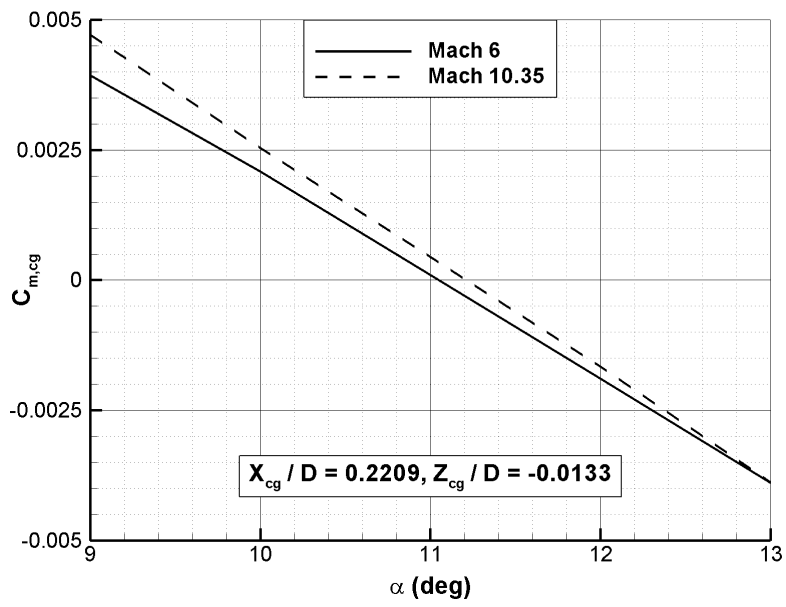

e. Pitching Moment Coefficient

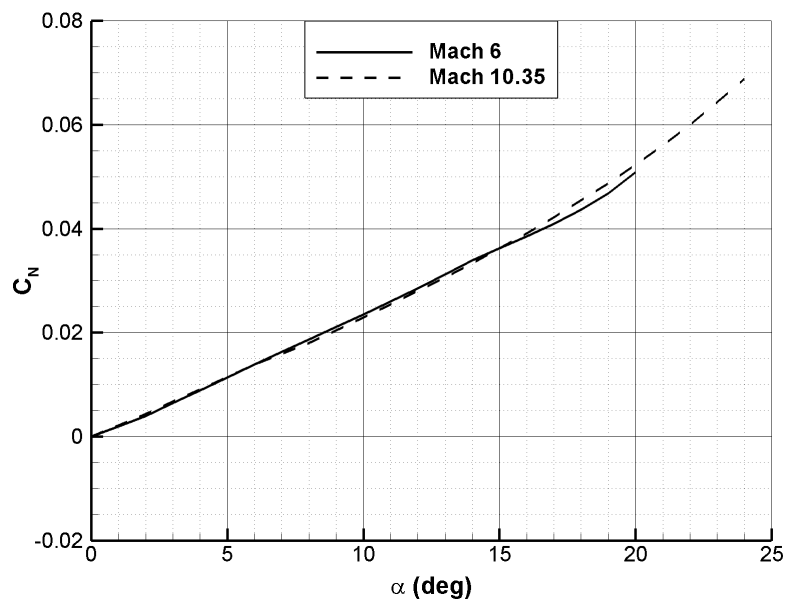

b. Normal Force Coefficient

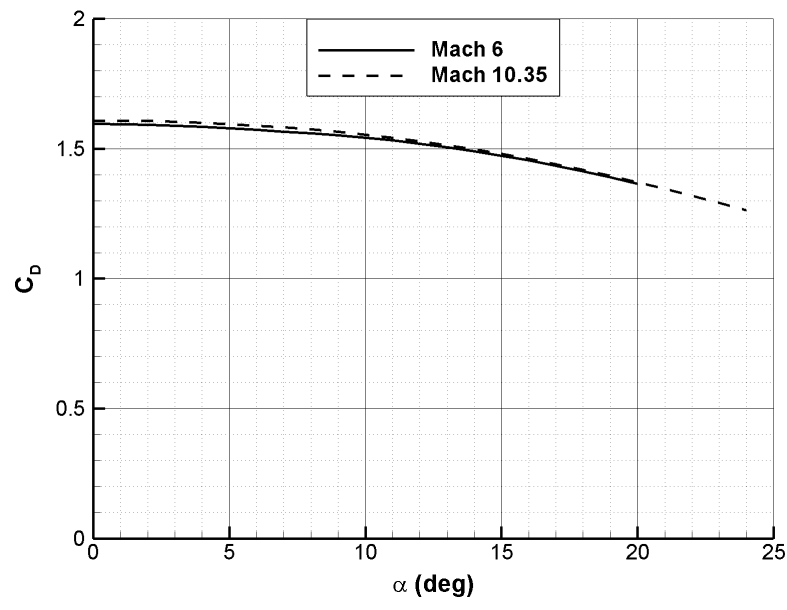

d. Drag Force Coefficient

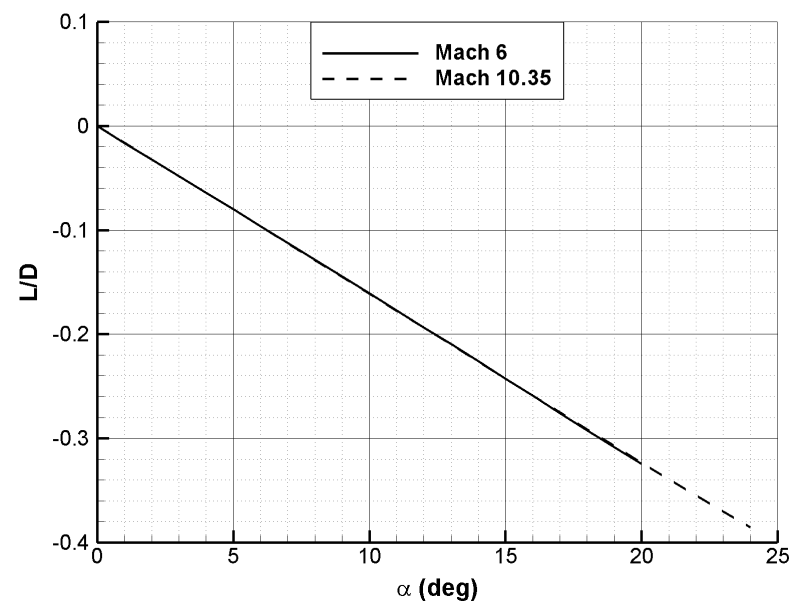

f. Lift-to-Drag Ratio

Figure 3. VLC Aerodynamic Coefficient Data vs. Angle-of-Attack at Mach 6 and 10.35 in Air 


\section{B. VL1 Flight Data}

Both VLC's were instrumented with five pressure ports on the aeroshell forebody, including one port for stagnation conditions. A reaction control system (RCS) was used for Viking to hold the attitude at the predicted trim angle of $-11.1 \mathrm{deg}$ at high altitudes. Once the sensed deceleration reached 0.05 Earth g's (at about $75 \mathrm{~km}$ ), the RCS was used to damp pitch and yaw attitude rates to below $1 \mathrm{deg} / \mathrm{sec}^{16}$. Roll control was used to keep the lift vector pointed upward. Otherwise, the entry capsule was allowed to seek out its natural trim angle; the RCS was not used to force a particular angle-ofattack. See Figure 4 for the RCS thruster and pressure port locations.

Reconstruction of the atmospheric profile (density, temperature, etc.) as a function of altitude is one of the major goals of the post-flight analysis of any Mars entry capsule. Typically, the force coefficients and atmospheric density cannot be independently measured during the entry and cannot be separated from one another. Rather, the aerodynamics is assumed to be known perfectly so that the density can be extracted. For example, the definition of axial force coefficient $\left(\mathrm{C}_{\mathrm{A}}\right)$ can be rearranged to solve for the product of $\mathrm{C}_{\mathrm{A}}$ and density:

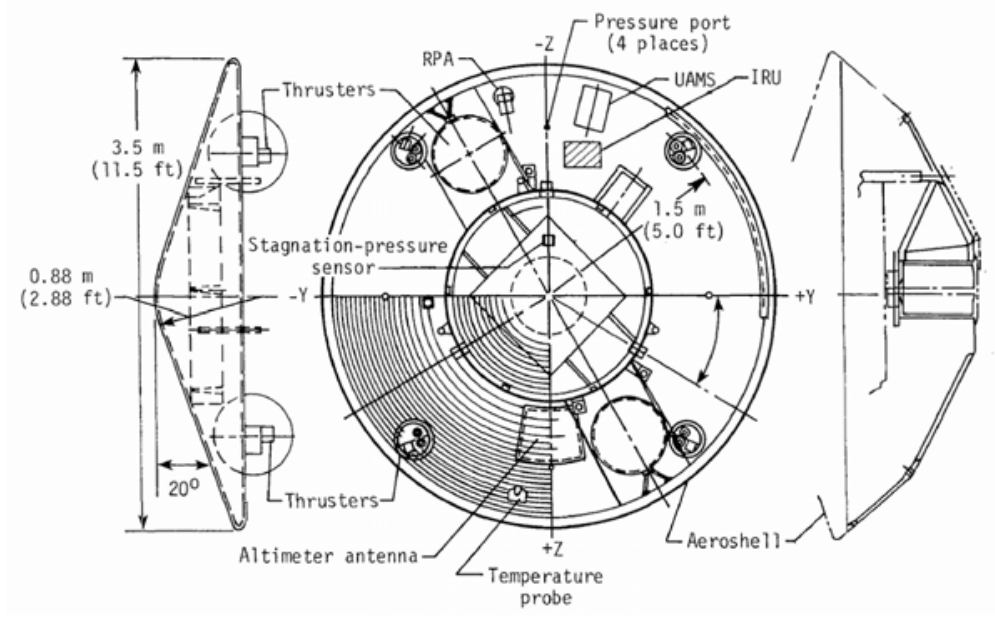

Figure 4. Viking Lander Capsule RCS and Instrumentation (from Ref. 16)

$$
\begin{gathered}
C_{A}=\frac{m A_{A}}{\frac{1}{2} \rho_{\infty} V_{\infty}^{2} S_{r e f}} \\
\rho_{\infty} C_{A}=\frac{2 m A_{A}}{V_{\infty}^{2} S_{r e f}}
\end{gathered}
$$

The terms on the right hand side are known from the on-board instrumentation and knowledge of the capsule geometry and mass. The two unknowns $\left(\mathrm{C}_{\mathrm{A}}\right.$ and $\left.\rho_{\infty}\right)$ cannot be separated unless there is an independent method for measuring the atmospheric density. Ground data can be used as a substitute for the actual flight $\mathrm{C}_{\mathrm{A}}$, but there are uncertainties that propagate into the calculation of density.

Fortunately, both flight VLC's were instrumented with pressure ports on the forebody. Reference 16 provides a detailed analysis of the use of the VL1 pressure and on-board accelerometer measurements to estimate aerodynamic coefficients in the free-molecular, transitional, and hypersonic continuum flight regimes. The analysis differed from the initial post-flight work in Reference 1 in that the pressure data were used in lieu of having a direct density measurement for Equation 5. The pressure and accelerometer data allowed the use of an iterative scheme to extract aerodynamic force coefficients in the body-reference frame ${ }^{16}$. Axial and normal force coefficients in the hypersonic continuum flow regime were extracted by using a rearranged form of Equation 4 :

$$
\begin{gathered}
C_{A}=\frac{C_{p, \text { stag }} m A_{A}}{p_{\text {stag }} S_{\text {ref }}} \\
C_{N}=\frac{C_{p, \text { stag }} m A_{N}}{p_{\text {stag }} S_{\text {ref }}}
\end{gathered}
$$


where $\mathrm{C}_{\mathrm{p}, \mathrm{stag}}$ is the hypersonic stagnation point pressure coefficient and is defined as:

$$
C_{p, \text { stag }}=\frac{p_{\text {stag }}}{\frac{1}{2} \rho_{\infty} V_{\infty}^{2} S_{\text {ref }}}
$$

The omission of static pressure from the pressure coefficient was considered to be negligible since the stagnation pressure was much higher ${ }^{16}$. The accelerations and stagnation pressure in Equations 3 and 4 were taken from the accelerometers and pressure ports, respectively. The pressure coefficient was estimated by assuming chemical equilibrium for altitudes below $40 \mathrm{~km}$ and using expansion tube data for altitudes above $40 \mathrm{~km}^{16}$. An iterative process was used starting from an initial estimate of the density profile and aerodynamic coefficients until convergence for both occurred. See Reference 16 for a detailed description of this iterative scheme.

Figure 5 shows the measured VL1 total angle-ofattack $\left(\alpha_{\mathrm{T}}\right)$ and $\mathrm{L} / \mathrm{D}$, where $\alpha_{\mathrm{T}}$ is the angle defined in the plane containing the velocity and lift vectors. The total angle was derived from on-board gyro data ${ }^{16}$. The design values for trim $\alpha_{T}$ and $L / D$ were $11.1 \mathrm{deg}$ and 0.18 based on perfect gas air tunnel data. The flight measurements show a gradual increase in total $\alpha$ from 10.5 deg to 12 deg with decreasing Mach number from 25 to 14 . Measured trim L/D for the same Mach number range is 0.16 to 0.19 . Oscillations at high Mach numbers reflect the vehicle motion at low dynamic pressures. Once the dynamic pressure builds up, the oscillations are damped out.

Figure 6 shows the velocity-altitude map for VL1. The VL1 Capsule entered the atmosphere at a relative velocity of $4.42 \mathrm{~km} / \mathrm{sec}$ and a relative flight path angle of $-17.63 \mathrm{deg}$ at $243.8 \mathrm{~km}^{16}$. The freestream conditions as a function of relative velocity are plotted in Figure 7. The symbols represent the velocities where CFD

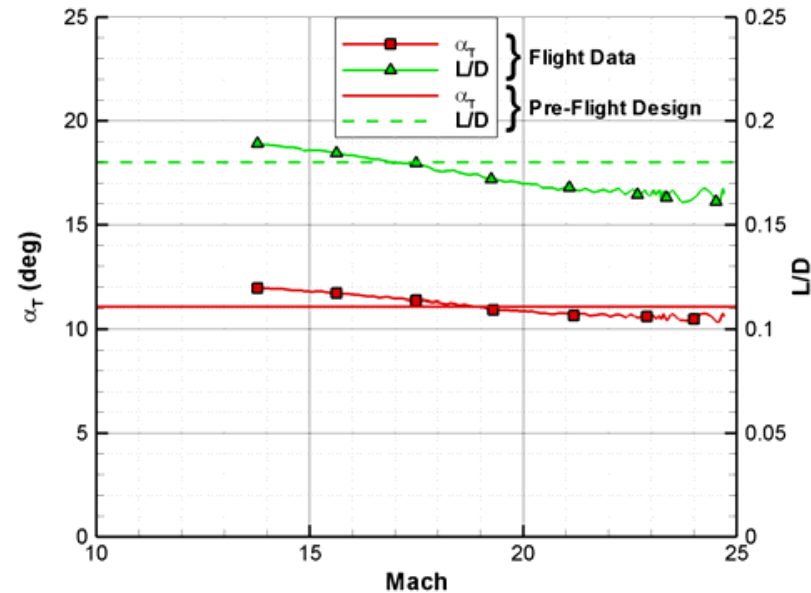

Figure 5. VL1 Total Angle-of-Attack and L/D vs. Mach Number: Measured and Pre-Flight Design Values (from Ref. 16) solutions were obtained. Table 2 summarizes the freestream conditions for the CFD cases. A density profile was not shown in Reference 16, so the profile from Reference 17 was used instead. That profile was derived from the VL1 and VL2 entries. The effects of density on computed aerodynamics are presented later.

\section{Computational Method}

Navier-Stokes solutions were obtained using the Langley Aerothermodynamic Upwind Relaxation Algorithm (LAURA) ${ }^{18}$ CFD code. LAURA has been used extensively to predict the aerodynamics and aerothermodynamics for Mars entry vehicles ${ }^{2-4,19-22}$. Perfect gas air conditions were used for the wind tunnel conditions and a finite-rate chemistry model was used for the flight conditions. At flight conditions, LAURA models the reaction mechanisms for an 8-species Mars gas $\left(\mathrm{CO}_{2}, \mathrm{CO}, \mathrm{N}_{2}, \mathrm{O}_{2}, \mathrm{NO}, \mathrm{C}, \mathrm{N}, \mathrm{O}\right)$ in chemical and thermal non-equilibrium using the Park$94^{23}$ reaction rates. In LAURA, the freestream is specified as $97 \% \mathrm{CO}_{2}$ and $3 \% \mathrm{~N}_{2}$ by mass and all solutions were run with a laminar boundary layer. Blunt-body aerodynamics are dominated by surface pressures, so the effects of the boundary layer state on shear stresses are negligible. A finite-volume approach is used to solve the full NavierStokes flowfield equations for all calculations presented here. The code uses Roe's averaging ${ }^{24}$ for the inviscid fluxes with second-order corrections using Yee's symmetric total variation diminishing (TVD) scheme ${ }^{25}$. 


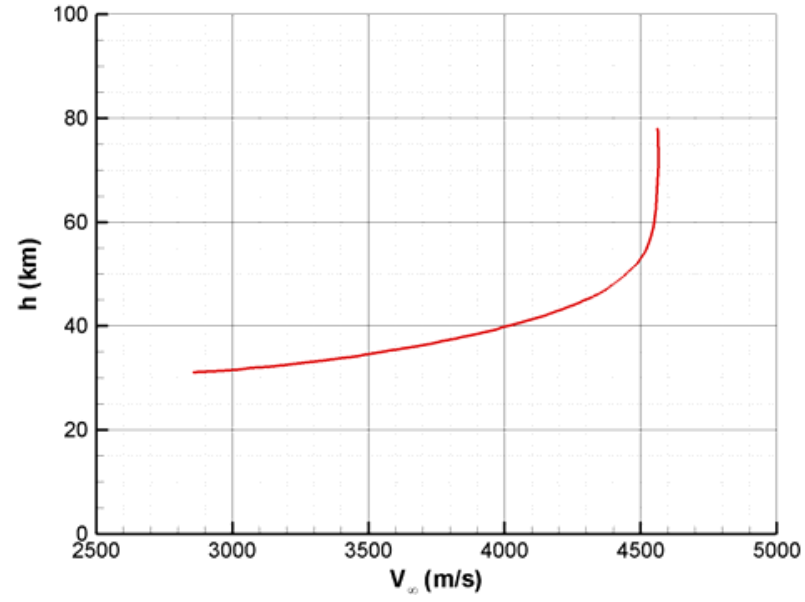

Figure 6. VL1 Altitude vs. Relative Velocity (from Ref. 16)

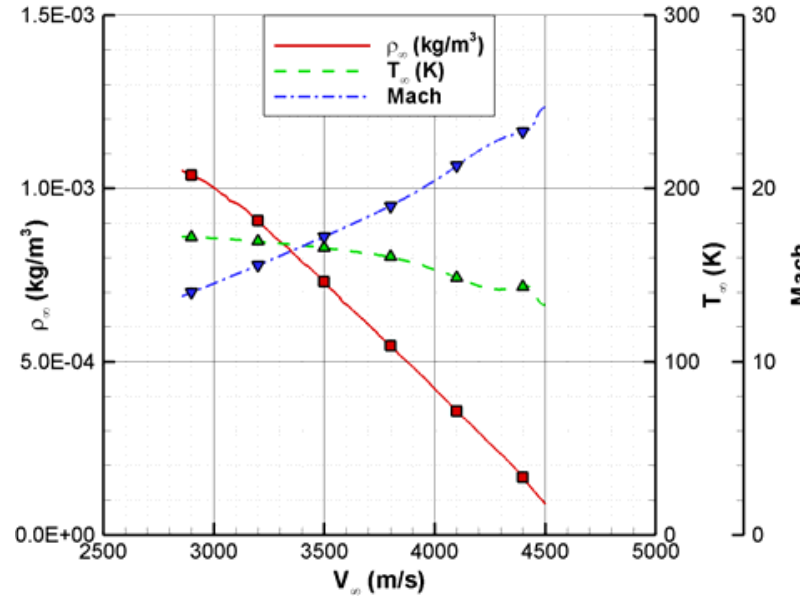

Figure 7. VL1 Density, Temperature, and Mach Number vs. Relative Velocity (CFD Solutions at Symbols)

Table 2. Freestream Conditions for CFD Solutions at VL1 Flight Conditions

\begin{tabular}{ccccccc}
\hline \hline $\mathrm{h}(\mathrm{km})$ & $\mathrm{V}_{\infty}(\mathrm{m} / \mathrm{sec})$ & $\rho_{\infty}\left(\mathrm{kg} / \mathrm{m}^{3}\right)$ & $\mathrm{T}_{\infty}(\mathrm{K})$ & Mach & $\mathrm{Re}_{\mathrm{D}} \times 10^{-6}$ & $\alpha_{\mathrm{T}}(\mathrm{deg})$ \\
\hline 31.2 & 2900 & $1.037 \times 10^{-3}$ & 171.8 & 14.0 & 1.22 & 11.93 \\
32.5 & 3200 & $0.907 \times 10^{-3}$ & 169.4 & 15.6 & 1.20 & 11.72 \\
34.5 & 3500 & $0.731 \times 10^{-3}$ & 165.7 & 17.2 & 1.08 & 11.44 \\
37.3 & 3800 & $0.545 \times 10^{-3}$ & 160.5 & 19.0 & 0.90 & 11.09 \\
41.3 & 4100 & $0.356 \times 10^{-3}$ & 148.3 & 21.3 & 0.70 & 10.71 \\
48.0 & 4400 & $0.165 \times 10^{-3}$ & 143.2 & 23.3 & 0.36 & 10.58 \\
\hline \hline
\end{tabular}

LAURA possesses the capability to adapt the computational mesh to the boundary layer and bow shock through user-defined parameters. In LAURA, a user-specified cell Reynolds number controls the grid spacing at the wall:

$$
\operatorname{Re}_{w}=\left(\frac{\rho a \Delta \eta}{\mu}\right)_{w}
$$

Grid adaptations are executed throughout the solution process until further adaptations do not significantly change the aerodynamics.

LAURA solutions were obtained on singularity-free structured volume grids. The forebody nose cap and afterbody base meshes do not have a singularity pole boundary that could otherwise introduce artificial discontinuities into the flowfield. Coarse and fine grids were used for both the sting models and flight capsule solutions. Figure 8 shows the Coarse surface grids. The Coarse grids have 64 cells in the surface normal direction. The fine grids have twice as many cells in each direction (4 times as many surface cells and 8 times as many volume cells). Table 2 summarizes the grids. The surface grid distribution used for the tunnel solutions is identical to the flight grid, with the addition of the sting.

\section{Results}

LAURA flowfield solutions were obtained for scale models of the VLC at tunnel conditions and for the fullscale entry capsule at VL1 flight conditions. Comparisons are made between the computed and measured static aerodynamic coefficients $\left(\mathrm{C}_{\mathrm{A}}, \mathrm{C}_{\mathrm{N}}, \mathrm{C}_{\mathrm{L}}, \mathrm{C}_{\mathrm{D}}, \mathrm{C}_{\mathrm{m}}\right.$, and $\left.\mathrm{L} / \mathrm{D}\right)$. At flight conditions, sensitivities to $\mathrm{CG}$ location, atmospheric density, and grid resolution are included in the computed results. 


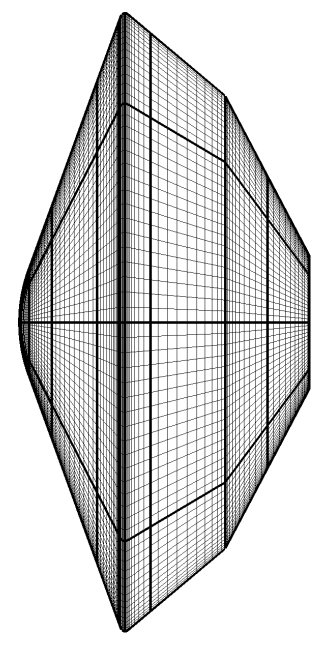

a. VL1 Entry Capsule

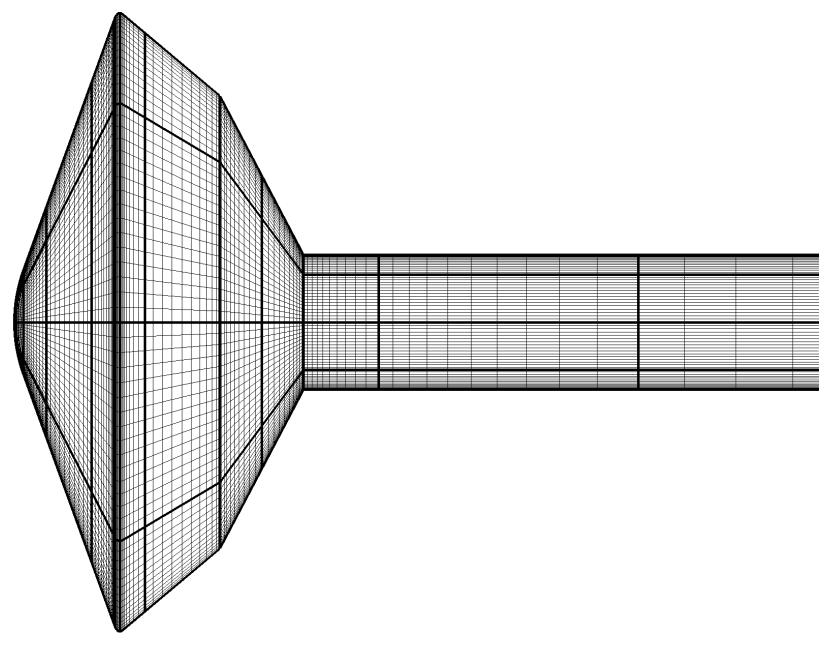

b. VLC Sting-Mounted Wind Tunnel Models

Figure 8. Coarse Surface Grids for LAURA Flowfield Solutions

Table 3. LAURA Computational Grids

\begin{tabular}{ccccc}
\hline \hline Grid & Surface Cells & Normal Cells & Volume Cells & $\mathrm{Re}_{\mathrm{w}}$ \\
\hline Coarse (Flight) & 6,144 & 64 & 393,216 & 1 \\
Fine (Flight) & 24,576 & 128 & $3,145,728$ & 0.5 \\
Coarse (Sting) & 8,192 & 64 & 524,288 & 1 \\
Fine (Sting) & 32,768 & 128 & $4,194,304$ & 0.5 \\
\hline \hline
\end{tabular}

\section{A. Comparison of LAURA and VLC Ground Test Data}

LAURA solutions were run for sting-mounted scale models of the VLC for Mach numbers 6 and 10.35. The sting was modeled in the flowfield solution, however forces and moments on the sting were not included in the aerodynamics. Calorically perfect air conditions with a constant $\gamma$ of 1.4 were used for both Mach numbers. Table 4 shows freestream conditions for both facilities. The conditions were not explicitly reported in Reference 2, so they had to be calculated based on knowledge of the reported dynamic pressure, Mach number, and Reynolds number. The expectation is that LAURA will do an excellent job of computing static aerodynamic characteristics under perfect gas hypersonic conditions. This assertion is based on good agreement with supersonic MSL data ${ }^{7-8}$ and the fact that hypersonic aerodynamics are dominated by the forebody pressure distribution.

Table 4. Freestream Conditions for CFD Solutions at VLC Hypersonic Facility Conditions

\begin{tabular}{cccccc}
\hline \hline Facility & $\mathrm{V}_{\infty}(\mathrm{m} / \mathrm{sec})$ & $\rho_{\infty}\left(\mathrm{kg} / \mathrm{m}^{3}\right)$ & $\mathrm{T}_{\infty}(\mathrm{K})$ & $\mathrm{M}_{\infty}$ & $\mathrm{Re}_{\mathrm{D}} \times 10^{-6}$ \\
\hline LaRC 20-Inch Mach 6 Air & 946.4 & $3.961 \times 10^{-2}$ & 62.8 & 6 & 1.24 \\
\hline LaRC 31-Inch CFHT & 1416.4 & $0.679 \times 10^{-2}$ & 46.7 & 10.35 & 0.32 \\
\hline \hline
\end{tabular}

Figure 9 shows symmetry plane Mach number contours with the sting at 20 deg angle-of-attack. Again, the forces and moments on the sting itself are not included in the computed aerodynamics. The shock-standoff distance is slightly larger for the Mach 6 conditions. At both Mach numbers, the afterbody and sting surface pressure coefficients are much lower than the forebody levels. 


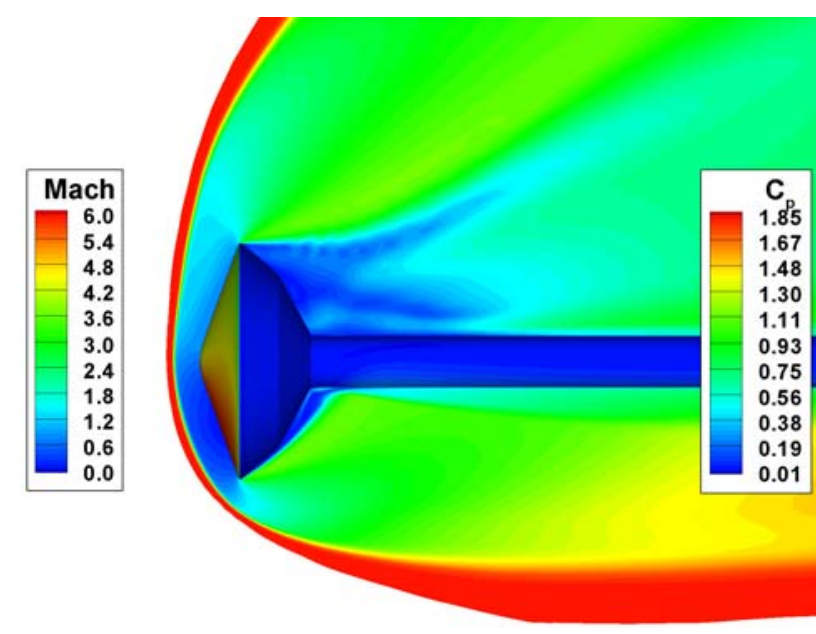

a. Mach 6 (3.48\% Scale Model)

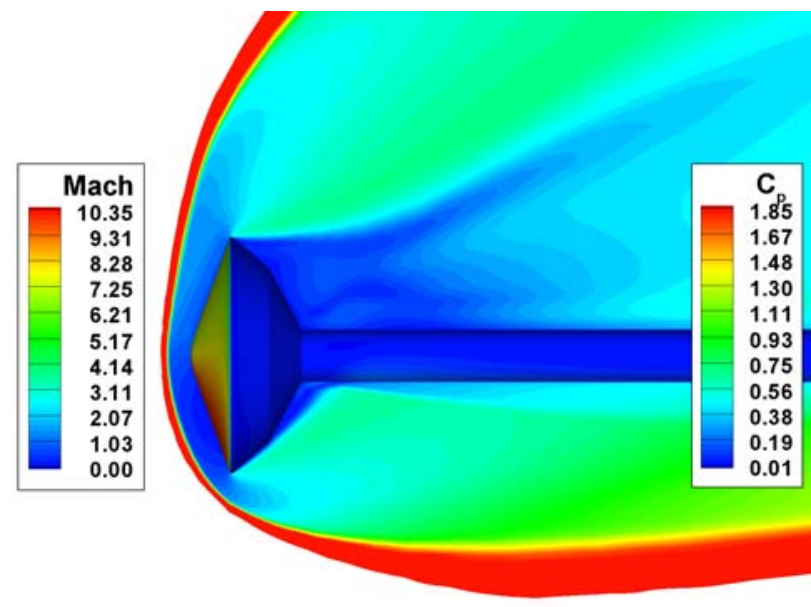

b. Mach 10.35 (2.75\% Scale Model)

Figure 9. LAURA VLC Mach Number and Surface Pressure Coefficient Contours at Tunnel Conditions ( $\alpha=20$ deg)

\section{LAURA Comparisons to Mach 6 Data}

Figure 10 shows LAURA results and tunnel data for the Mach 6 conditions. LAURA $C_{A}$ is about $2 \%$ below the data, an amount which is approximately equal to the measurement uncertainty (Fig. 10a). The uncertainty is a combination of the balance uncertainty and run-to-run variation. The fine grid $\mathrm{C}_{\mathrm{A}}$ results are slightly better than the coarse grid results, but the differences are negligible. Computed $\mathrm{C}_{\mathrm{N}}$ is within the data uncertainty for both grids. Regardless, $\mathrm{C}_{\mathrm{N}}$ is a very small contributor to $\mathrm{C}_{\mathrm{L}}$ or $\mathrm{C}_{\mathrm{D}}$ for 70 -deg sphere-cone geometries. Lift and drag coefficient are computed to within $1 \%$ and $2 \%$ of the data, respectively. This follows that result that $\mathrm{C}_{\mathrm{A}}$ is well computed and is the primary contributor to $C_{L}$ and $C_{D}$. Pitching moment coefficient referenced to the flight $C G$ location $\left(C_{m, c g}\right)$ is shown on an expanded scale in Figure 10e. The computed trim angle is within $0.3 \mathrm{deg}$ of the data for both computational grids. The computed pitching moment static stability $\left(\mathrm{C}_{\mathrm{m}_{\alpha}}\right)$ is slightly shallower (i. e. less stable) than the data indicate. Figure 10f shows that the agreement in $\mathrm{L} / \mathrm{D}$ is excellent for a given $\alpha$. LAURA is within $1 \%$ of the $\mathrm{L} / \mathrm{D}$ data regardless of grid resolution.

Table 5 summarizes the LAURA results and tunnel data at their respective trim angles using the flight CG location. The percent differences between the LAURA results and data are shown in parentheses. LAURA results on the fine grid results in a slightly higher trim angle. Trim $\mathrm{C}_{\mathrm{A}}$ on both computational grids are within $2 \%$ of the data. Similar agreement is shown for trim $C_{L}$ and $C_{D}$. Computed trim $L / D$ is slightly closer to the data because the trim angle is closer. Pitching moment slope is better computed using the fine grid. No attempt was made to determine sensitivities of the computed aerodynamic coefficients to freestream condition perturbations.

Table 5. Summary of VLC Mach 6 Data, LAURA Results, and Percent Differences at Trim Conditions $\left(X_{\mathrm{cg}} / \mathrm{D}=\mathbf{0 . 2 2 0 9}, \mathrm{Z}_{\mathrm{cg}} / \mathrm{D}=\mathbf{- 0 . 0 1 3 3}\right)$

\begin{tabular}{cccccccc}
\hline \hline Data & Trim $\alpha(\mathrm{deg})$ & $\mathrm{C}_{\mathrm{A}}$ & $\mathrm{C}_{\mathrm{N}}$ & $\mathrm{C}_{\mathrm{L}}$ & $\mathrm{C}_{\mathrm{D}}$ & $\mathrm{L} / \mathrm{D}$ & $\mathrm{C}_{\mathrm{m}_{\alpha}}$ \\
\hline Tunnel & 11.05 & 1.555 & 0.0261 & -0.2723 & 1.531 & -0.1779 & -0.00198 \\
\hline \multirow{2}{*}{ LAURA (Coarse) } & \multirow{2}{*}{11.19} & 1.527 & 0.0244 & -0.2722 & 1.502 & -0.1813 & -0.00173 \\
& & $(-1.81 \%)$ & $(-6.64 \%)$ & $(-0.06 \%)$ & $(-1.87 \%)$ & $(1.91 \%)$ & $(-12.63 \%)$ \\
\hline \multirow{2}{*}{ LAURA (Fine) } & \multirow{2}{*}{11.36} & 1.529 & 0.0251 & -0.2764 & 1.504 & -0.1839 & -0.00189 \\
& $(-1.67 \%)$ & $(-3.95 \%)$ & $(1.49 \%)$ & $(-1.78 \%)$ & $(3.38 \%)$ & $(-4.55 \%)$ \\
\hline \hline
\end{tabular}

\section{LAURA Comparisons to Mach 10.35 Data}




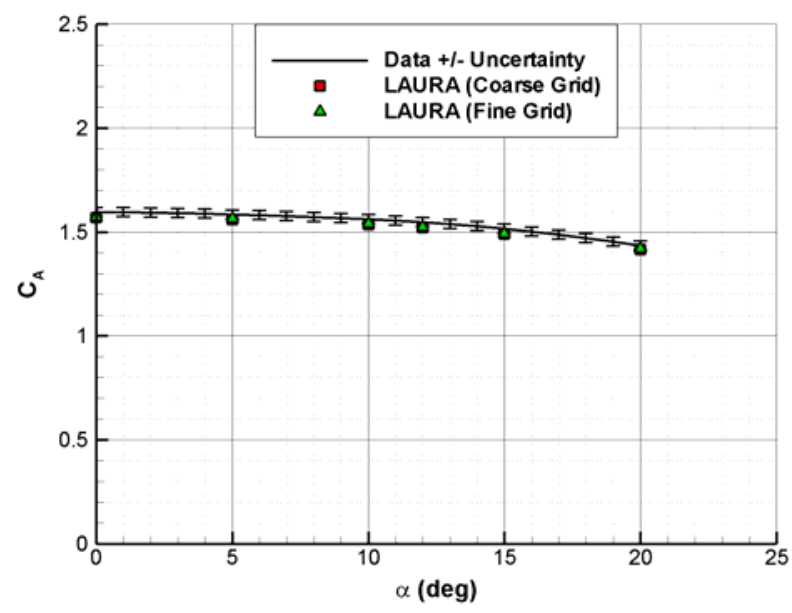

a. Axial Force Coefficient

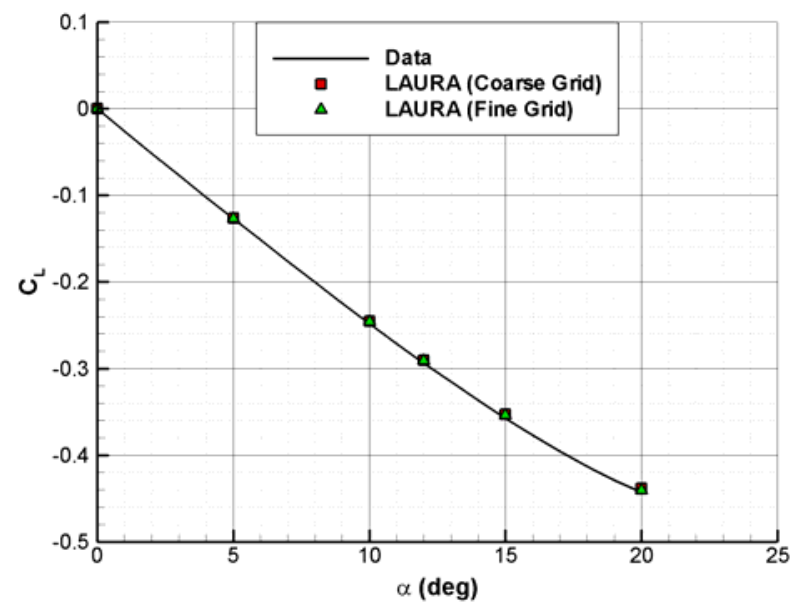

c. Lift Force Coefficient

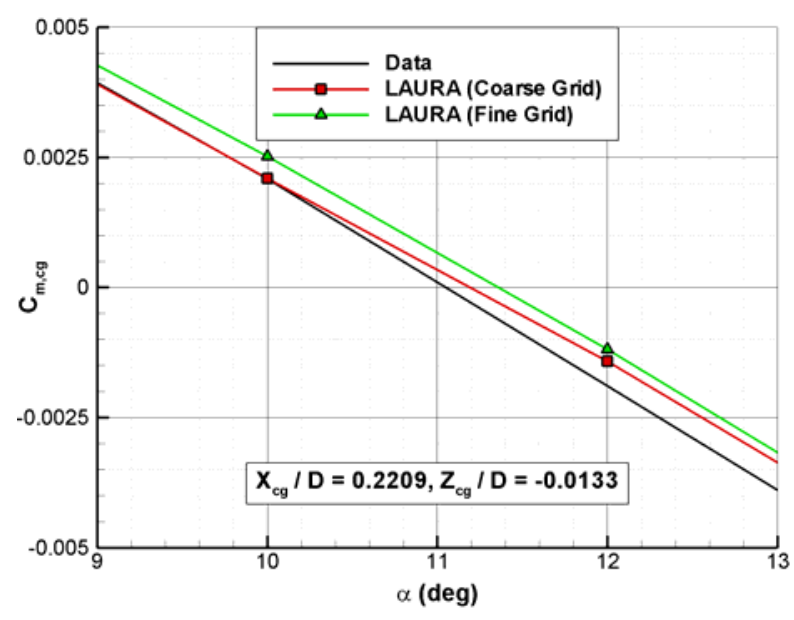

e. Pitching Moment Coefficient

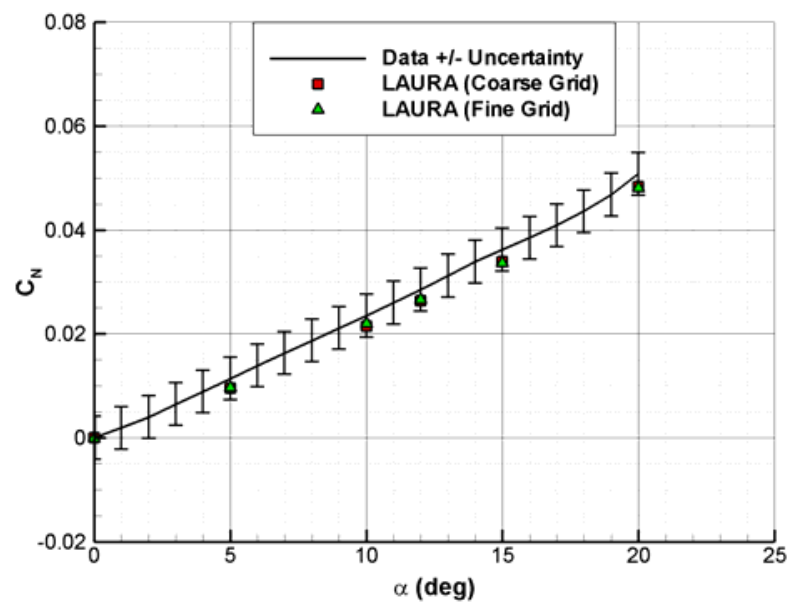

b. Normal Force Coefficient

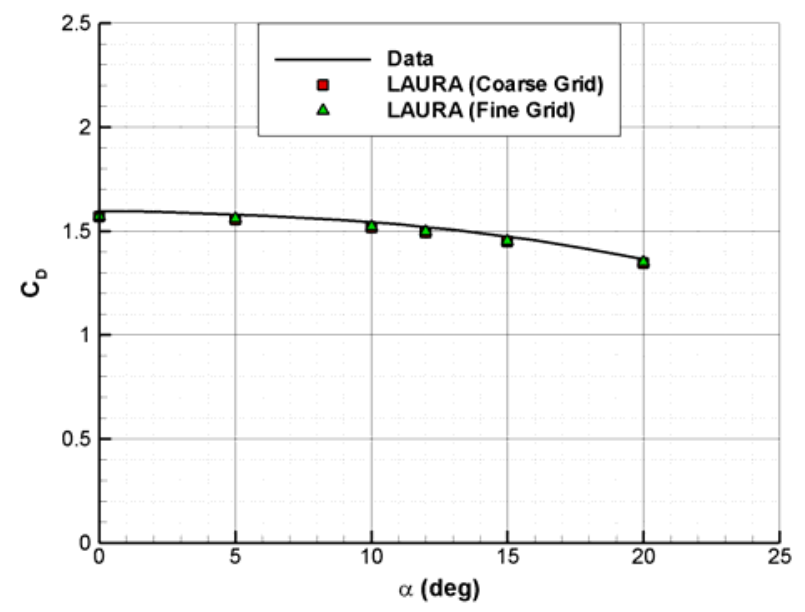

d. Drag Force Coefficient

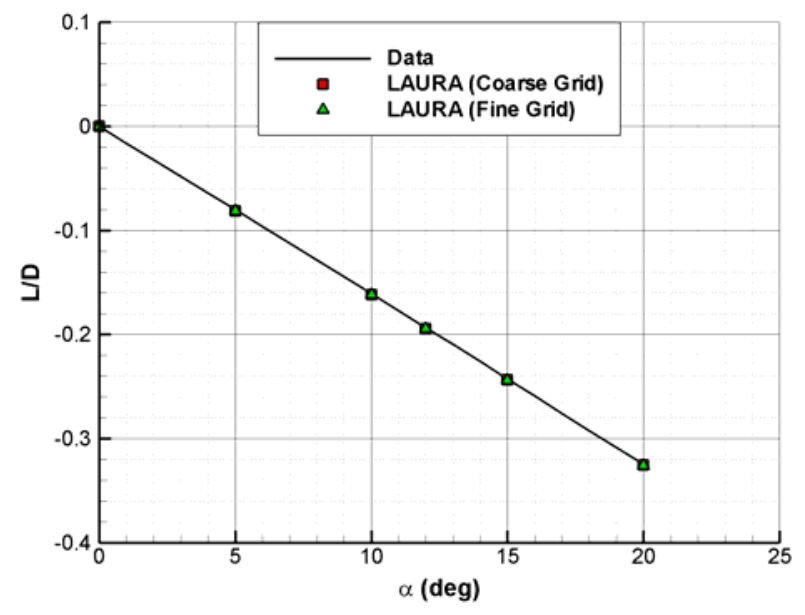

f. Lift-to-Drag Ratio

Figure 10. LAURA VLC Aerodynamic Coefficients vs. Angle-of-Attack Compared to Mach 6 Data in Air 


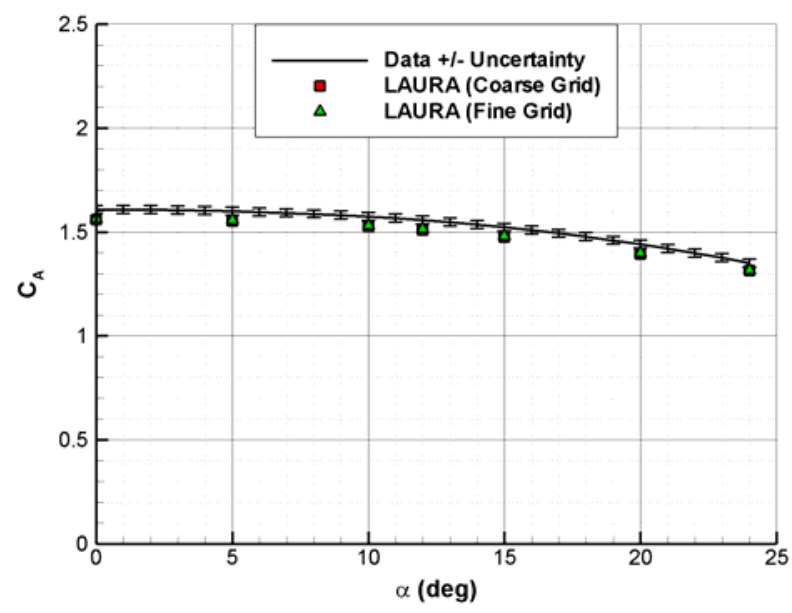

a. Axial Force Coefficient

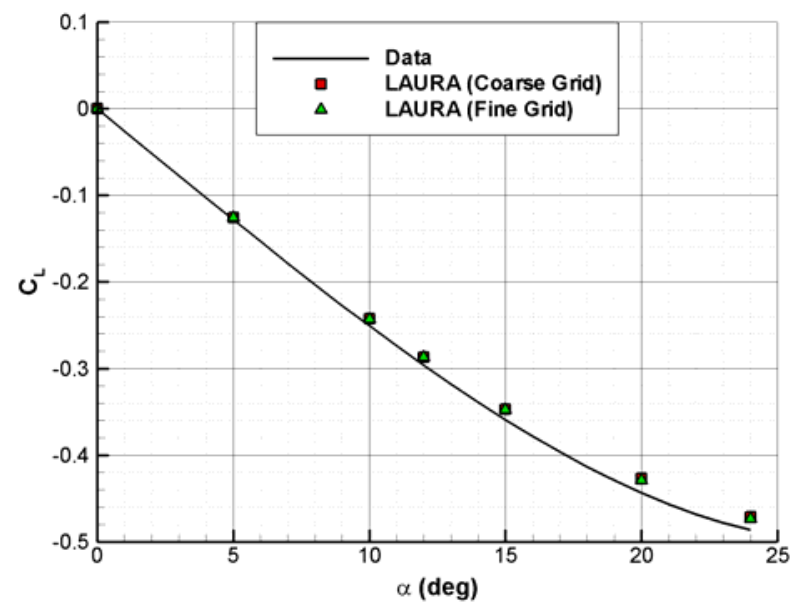

c. Lift Force Coefficient

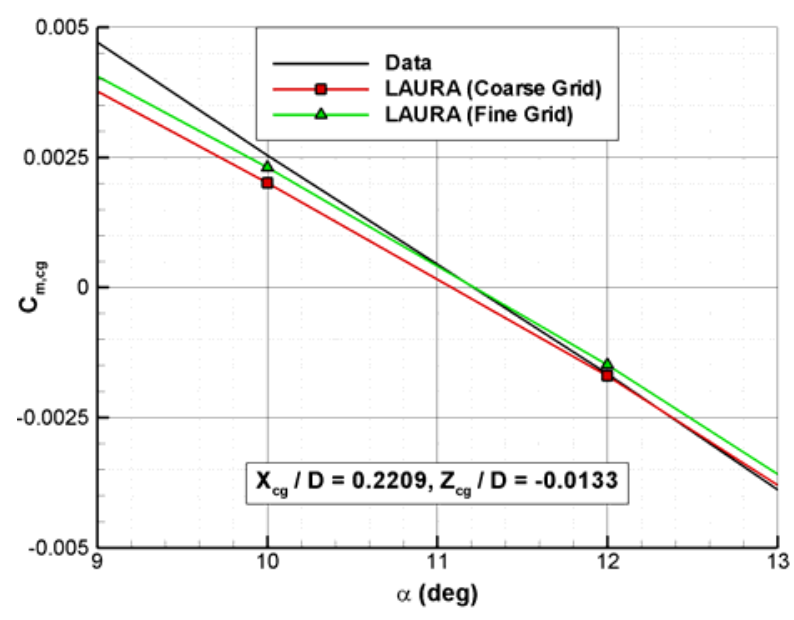

e. Pitching Moment Coefficient

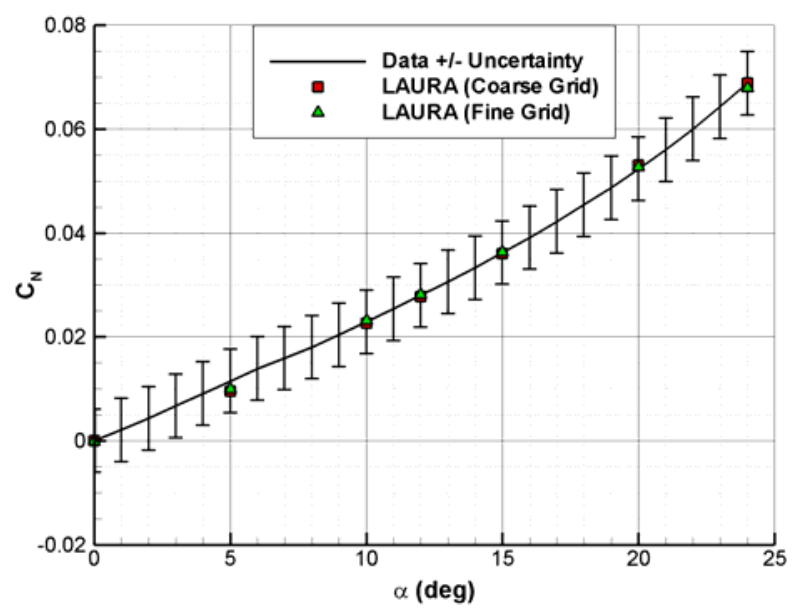

b. Normal Force Coefficient

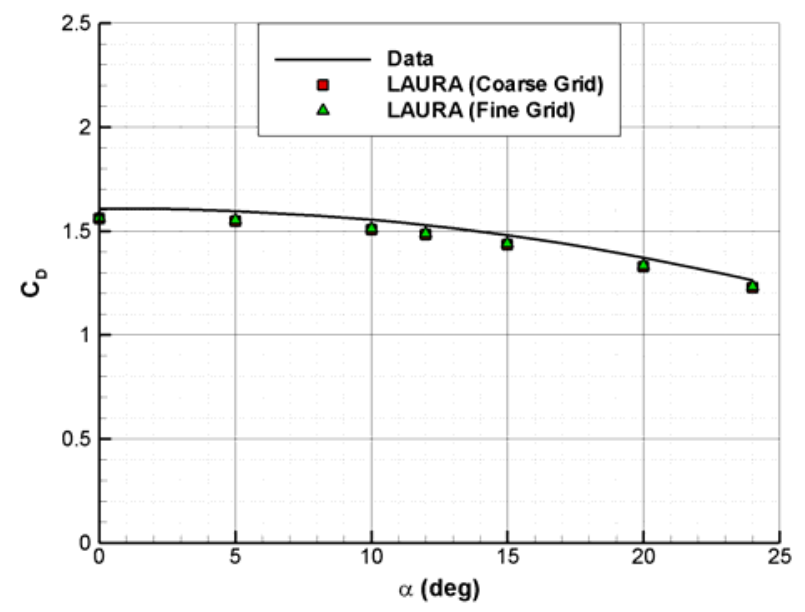

d. Drag Force Coefficient

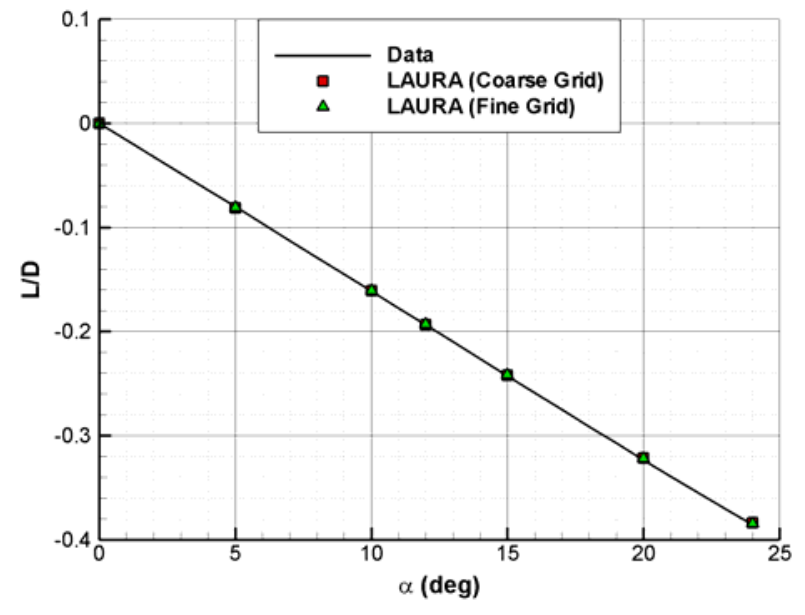

f. Lift-to-Drag Ratio

Figure 11. LAURA VLC Aerodynamic Coefficients vs. Angle-of-Attack Compared to Mach 10.35 Data in Air 
Figure 11 shows LAURA and tunnel data for the Mach 10.35 conditions. The results are very similar to the Mach 6 computations. In general, LAURA slightly underpredicts the coefficients for all angles. At the same angleof-attack, computed $\mathrm{C}_{\mathrm{L}}$ and $\mathrm{C}_{\mathrm{D}}$ are both within $3 \%$ of the data. LAURA L/D is within $1 \%$ of the data at all angles. Table 6 shows the trim coefficients. Computed trim angle is within $0.13 \mathrm{deg}$ of the data for both computational grids. The fine grid results are closer to the data, but both sets of data show excellent agreement with the tunnel measurements. Pitching moment slope using the flight CG location is better computed with the fine grid.

Table 6. Summary of VLC Mach 10.35 Data, LAURA Results, and Percent Differences at Trim Conditions $\left(X_{\mathrm{cg}} / \mathrm{D}=\mathbf{0 . 2 2 0 9}, \mathrm{Z}_{\mathrm{cg}} / \mathrm{D}=\mathbf{- 0 . 0 1 3 3}\right)$

\begin{tabular}{cccccccc}
\hline \hline Data & Trim $\alpha(\mathrm{deg})$ & $\mathrm{C}_{\mathrm{A}}$ & $\mathrm{C}_{\mathrm{N}}$ & $\mathrm{C}_{\mathrm{L}}$ & $\mathrm{C}_{\mathrm{D}}$ & $\mathrm{L} / \mathrm{D}$ & $\mathrm{C}_{\mathrm{m}_{\alpha}}$ \\
\hline Tunnel & 11.21 & 1.564 & 0.0259 & -0.2786 & 1.539 & -0.1810 & -0.00210 \\
\hline \multirow{2}{*}{ LAURA (Coarse) } & \multirow{2}{*}{11.08} & 1.517 & 0.0254 & -0.2665 & 1.494 & -0.1785 & -0.00183 \\
& & $(-3.00 \%)$ & $(-2.15 \%)$ & $(-4.35 \%)$ & $(-2.96 \%)$ & $(-1.36 \%)$ & $(-12.86 \%)$ \\
\hline \multirow{2}{*}{ LAURA (Fine) } & \multirow{2}{*}{11.22} & 1.520 & 0.0262 & -0.2699 & 1.496 & -0.1806 & -0.00194 \\
& & $(-2.82 \%)$ & $(0.88 \%)$ & $(-3.12 \%)$ & $(-2.82 \%)$ & $(-0.24 \%)$ & $(-7.62 \%)$ \\
\hline \hline
\end{tabular}

\section{B. Comparison of LAURA and VL1 Flight Data}

As expected, LAURA does well to compute hypersonic aerodynamics for sting-mounted wind tunnel models in calorically perfect air. However, the prediction of hypersonic aerodynamics at angle-of-attack in a chemicallyreacting $\mathrm{CO}_{2}-\mathrm{N}_{2}$ gas is a more important measure since CFD methods are used for flight calculations. The VL1 data presents a unique opportunity to calibrate CFD methods at flight conditions for non-zero angle-of-attack. LAURA solutions were obtained at flight conditions for the VL1 entry trajectory at the freestream conditions shown in Table 2. One set of solutions was obtained for the measured angle-of-attack. A second set of solutions was obtained in order to determine the CFD-based trim angle using the capsule's CG location. Sensitivities to CG location, atmospheric density, and grid refinement were also examined.

\section{LAURA Comparisons to VL1 Flight Data at Measured Angle-of-Attack}

Figure 12 shows the VL1 $C_{L}, C_{D}$, and L/D flight data compared to LAURA solutions at the measured angle-ofattack. This comparison gives a measure of LAURA for predicting aerodynamics at a given angle-of-attack. Figure 12a shows LAURA flowfield for the Mach 14 condition. The hypersonic shock layer lies very close to the body and the afterbody pressure coefficient is low. The effects of the afterbody on aerodynamics were expected to be small, but their effects were included in the calculations unless otherwise stated. Figure 12b-c compare computed full capsule and forebody-only aerodynamics. The coefficients for the full capsule and forebody are nearly identical for all Mach numbers considered. LAURA $\mathrm{C}_{\mathrm{L}}$ data are up to 3\% below the flight data and the agreement is better with increasing Mach number. Similarly, LAURA $C_{D}$ is up to $5 \%$ below the data for lower Mach numbers. Possible reasons for the local peak measured $C_{D}$ near Mach 18 are unknown. The forebody-only $C_{D}$ is slightly above the full capsule drag coefficient for all Mach numbers. The underprediction of $C_{L}$ and $C_{D}$ indicates an underprediction of $\mathrm{C}_{\mathrm{A}}$. The shape of the flight $\mathrm{L} / \mathrm{D}$ curve is reproduced very well by the computations, with a slight shift upward. Computed L/D is about 3\% above the flight data for all Mach numbers considered. This good $\mathrm{L} / \mathrm{D}$ agreement is consistent with the tunnel results, which shows excellent $\mathrm{L} / \mathrm{D}$ agreement for a particular angle-of-attack. Also, since $\mathrm{C}_{\mathrm{L}}$ and $\mathrm{C}_{\mathrm{D}}$ are dominated by $\mathrm{C}_{\mathrm{A}}$, and are both below the data, a misprediction of $\mathrm{C}_{\mathrm{A}}$ will not show up as much in L/D. 


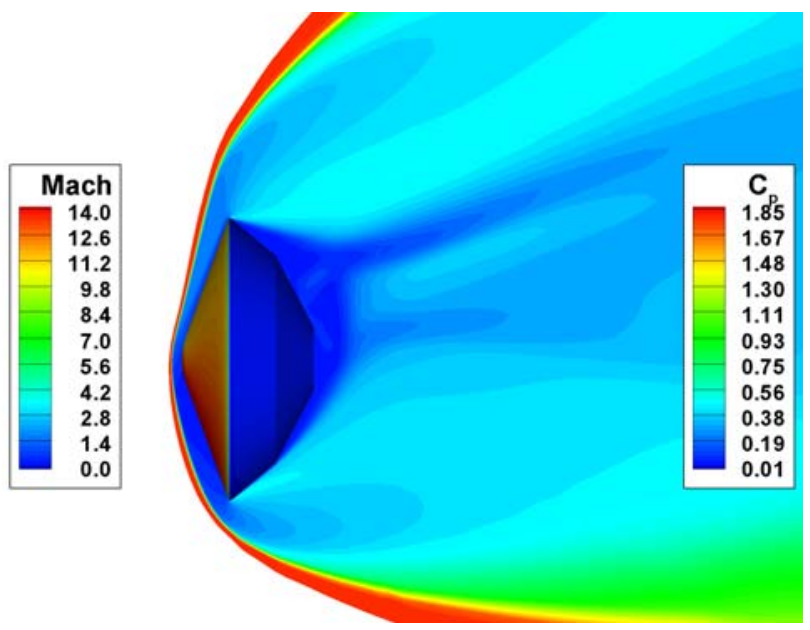

a. Mach Number and Surface Pressure Coefficient Contours at Mach 14

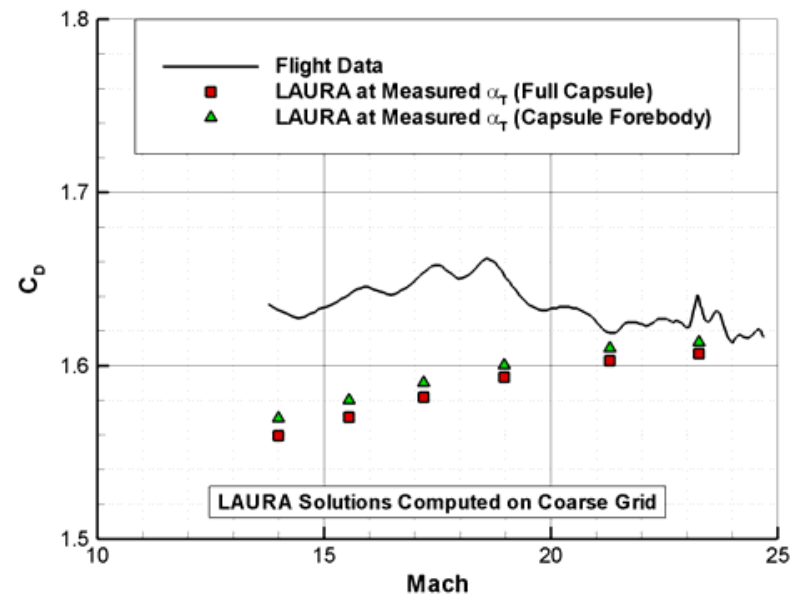

c. Drag Force Coefficient

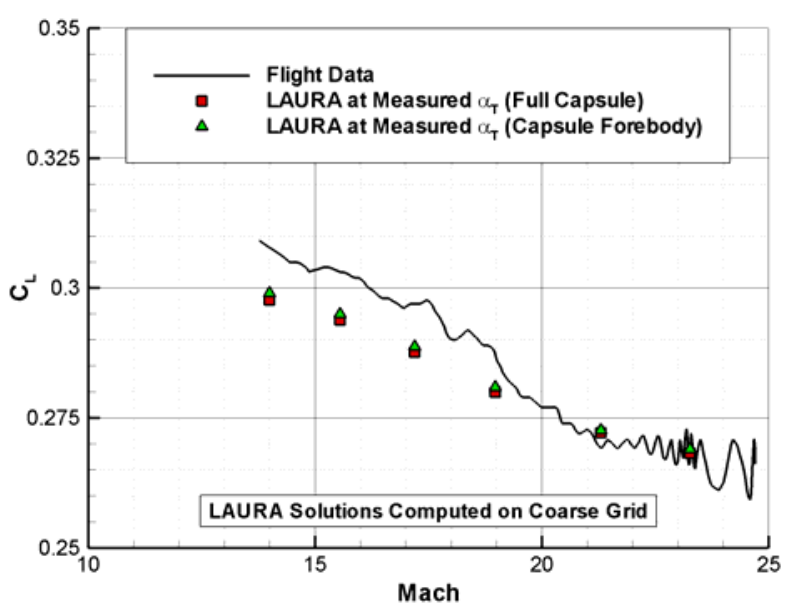

b. Lift Force Coefficient

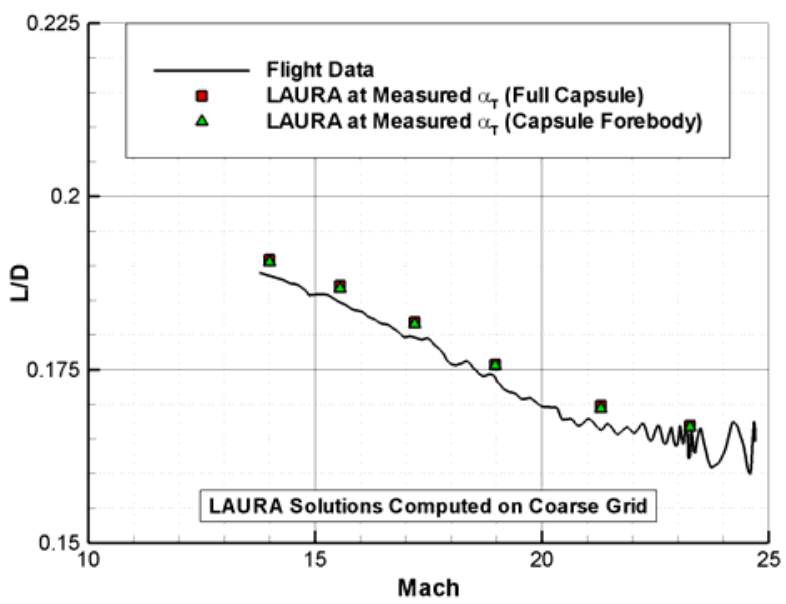

d. Lift-to-Drag Ratio

Figure 12. VL1 Capsule Aerodynamic Coefficients vs. Mach Number: LAURA Results at Measured Angleof-Attack Compared to Flight Data

\section{LAURA Comparisons to VL1 Flight Data at Computed Trim Angle-of-Attack}

Good agreement between computations and VL1 flight coefficients at the same angle-of-attack is somewhat expected at hypersonic velocities. However, those comparisons do not reveal the true uncertainties of using CFD for hypersonic aerodynamics prediction. A more important question that can be answered using the VL1 data is how well CFD methods would have predicted the trim $\alpha, C_{L}, C_{D}$, and $L / D$. In the absence of modern computational tools, the pre-flight VL1 trim angle was expected to be near -11.1 deg based on the ground-based wind tunnel aerodynamics in calorically perfect air. The VL1 flight data shows a trim angle that varies between 10.5 and 12 deg for Mach numbers from 25 down to 14 (Fig. 5).

Using modern computational methods that are capable of finite-rate chemical reactions in a predominantly $\mathrm{CO}_{2}$ atmosphere, the trim angle can be predicted for a range of entry conditions using the pitching moment curves. For the MPF and MER entry capsules, the aerodynamics databases consisted primarily of LAURA CFD solutions for a prescribed entry trajectory (velocity vs. altitude). CFD solutions were obtained at each trajectory point for a range of angles-of-attack that bounded the expected trim angle. One product of the database is a prediction of the stable 
trim angle for a given CG location. Using that approach, the MPF pre-flight entry trajectory simulations identified bounded static instabilities $\left(\mathrm{C}_{\mathrm{m}_{\alpha}}>0\right.$ at $\left.\alpha=0\right)$ that were predicted by the LAURA $\mathrm{C}_{\mathrm{m}, \mathrm{cg}}$ vs. $\alpha$ curves $^{2}$. Pre-flight simulations of the EDL system often use three degree-of-freedom aerodynamics at the trim angle to estimate system performance. Full six degree-of-freedom simulations use the $\mathrm{C}_{\mathrm{m}, \mathrm{cg}}$ vs. $\alpha$ curves to determine the capsule orientation. Both methods require accurate CFD-based aerodynamics with appropriate uncertainties. In order to determine the VL1 trim angle computed by LAURA, additional solutions were obtained that allowed generation of $\mathrm{C}_{\mathrm{m}, \mathrm{cg}}$ vs. $\alpha$ curves along the VL1 trajectory. Only one additional solution was required at each Mach number since the measured and computed trim angles were close to one another and the aerodynamics are linear near $\alpha=11 \mathrm{deg}$.

Figure 13a shows the measured angle-of-attack compared to the trim angle derived from LAURA computations. Again, results from the full capsule and capsule forebody are shown, both with the coarse grid. Overall, LAURA gives a flatter trim angle curve than is shown by the data. LAURA does a better job of calculating the trim angle at higher Mach numbers and tends to underpredict more with decreasing Mach number (Fig. 13a). Even then, the LAURA trim angle is within $0.5 \mathrm{deg}$ of the measured angle for all Mach numbers considered. Computed trim $\mathrm{C}_{\mathrm{L}}$, $\mathrm{C}_{\mathrm{D}}$, and L/D match the data the best at higher Mach numbers, where measured and LAURA trim angles are the closest. The general underprediction of trim angle at lower Mach numbers moves the LAURA trim $\mathrm{C}_{\mathrm{L}}$ further below the flight data. Computed CD is also in better agreement with flight data at higher Mach numbers (Fig. 13c). The LAURA trim $C_{D}$ results are virtually unaffected by the small differences in the measured and calculated trim

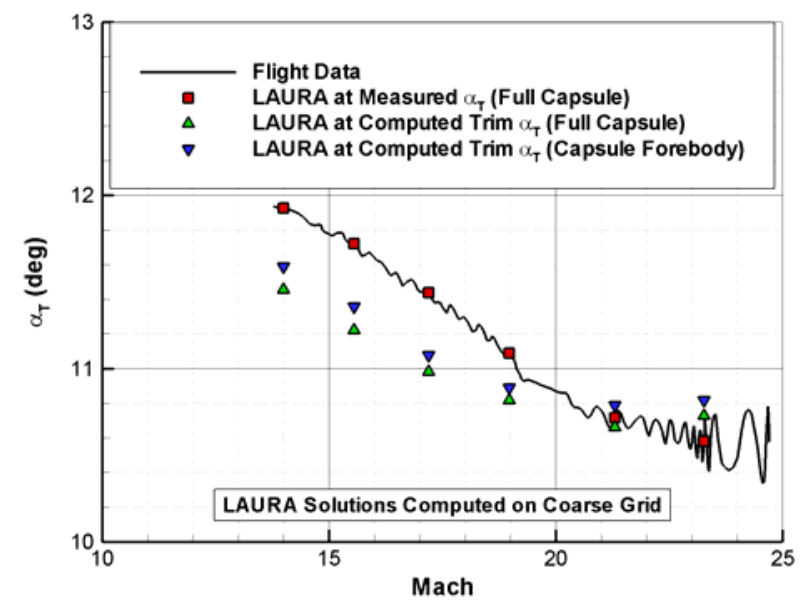

a. Total Angle-of-Attack

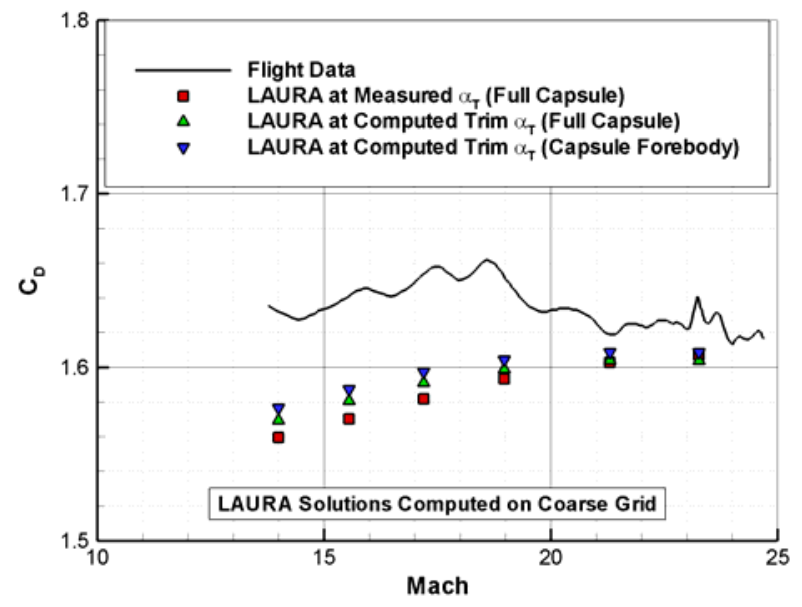

c. Drag Force Coefficient

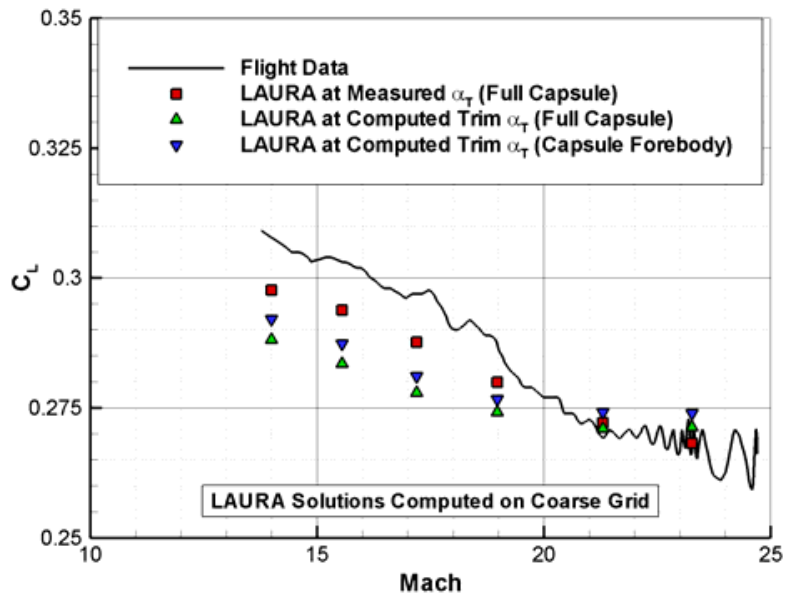

b. Lift Force Coefficient

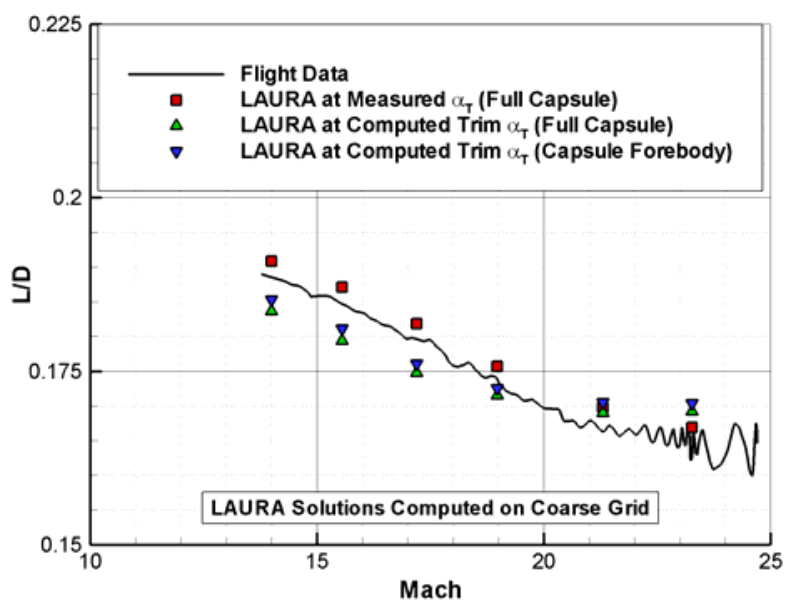

d. Lift-to-Drag Ratio

Figure 13. VL1 Capsule Aerodynamics vs. Mach Number: LAURA Results at Computed Trim Angle-ofAttack Compared to Flight Data 
angle. This is true because $\mathrm{C}_{\mathrm{D}}$ is dominated by the $C_{A} \cos \alpha$ term in Equation 2 and $\partial \mathrm{C}_{\mathrm{D}} / \partial \alpha$ is small for the angles considered. LAURA trim $\mathrm{C}_{\mathrm{D}}$ is within $5 \%$ of the flight data, with better agreement at higher Mach numbers. The quality of the LAURA trim L/D calculations follows the quality of the trim angle results. LAURA predicts trim L/D better at Mach numbers where the trim angle calculation is better. This is to be expected since LAURA L/D is within $1 \%$ of hypersonic wind tunnel data for a given angle-of-attack. This underscores the importance of predicting the correct trim angle as a function of Mach number i. e. the $\mathrm{C}_{\mathrm{m}, \mathrm{cg}}$ vs. $\alpha$ curves.

Using the LAURA solutions along the prescribed density profile, the pre-flight trim angle-of-attack would have been between approximately $10.7 \mathrm{deg}$ at Mach 23.3 and 11.5 deg at Mach 14. The trim L/D would have been predicted to vary between 0.17 and 0.185 for the same Mach number range. Of course, the original VL1 entry path (velocity vs. altitude) assumed aerodynamic coefficients based on the wind tunnel data in air. Had CFD predictions been available, the pre-flight entry path would have been slightly different than the one used here. The assumption for Mars entry vehicles since Viking is that aerodynamic uncertainties cover the possibility that the actual entry path will deviate from the predicted one. Sensitivities of computed trim aerodynamics to atmospheric density are shown in a later section.

Monte-Carlo analyses of entry systems require uncertainties for the various models that simulate the system. The aerodynamics model $\left(\mathrm{C}_{\mathrm{A}}, \mathrm{C}_{\mathrm{N}}, \mathrm{C}_{\mathrm{m}, \mathrm{cg}}\right.$ vs. Mach and $\left.\alpha\right)$ has uncertainties associated with it that represent uncertainties in predicting aerodynamics using CFD and experimental methods. The MPF and MER hypersonic aerodynamics, which were predicted with LAURA, had uncertainties for the body-axis coefficients $\left(\mathrm{C}_{\mathrm{A}}, \mathrm{C}_{\mathrm{N}}, \mathrm{C}_{\mathrm{m}}\right)$. The 3- $\sigma$ hypersonic $C_{A}\left(=C_{D}\right.$ for trim $\left.\alpha=0\right)$ uncertainty was specified as $2 \%$ for MPF and $3 \%$ for MER ${ }^{26}$. The LAURA trim $\mathrm{C}_{\mathrm{D}}$ for VL1 is as much as $5 \%$ below the measured flight data, so a 2-3\% 3- $\sigma$ uncertainty may be overly optimistic at hypersonic Mach numbers closer to 14 . Errors in the process used to derive VL1 $C_{A}$ and $C_{N}$ (Equations 6 and 7) were not quantified in Reference 16, so the data bounds on flight $C_{D}$ are not known.

\section{Sensitivity of LAURA Computed Trim Conditions to Radial CG Location}

The LAURA results so far have assumed the nominal CG location reported in Reference 9. An off-nominal CG location would change the $\mathrm{C}_{\mathrm{m}, \mathrm{cg}}$ vs. $\alpha$ curves (via Eqn. 3), and thus change the trim angle. Post-flight analysis showed that the observed VL1 L/D was higher than expected, possibly due to an off-nominal CG location or shape change effects due to ablation ${ }^{1}$. Reference 1 states that the axial $\left(\mathrm{X}_{\mathrm{cg}}\right)$ and radial $\left(\mathrm{Z}_{\mathrm{cg}}\right) \mathrm{CG}$ uncertainties for the flight capsule were approximately 0.06 in. and 0.025 in., respectively. These uncertainties result from measurement tolerances and biases, as well as fuel mass migration. The trim angle is a much stronger function of $Z_{\mathrm{cg}}$ since the $\mathrm{C}_{\mathrm{A}}$ term dominates Equation 3. The radial CG location was adjusted by $+/-0.025$ in. and the trim angle comparisons were repeated. Figure 14 shows the resulting trim angle using the nominal and dispersed $\mathrm{Z}_{\mathrm{cg}}$ locations. The effect

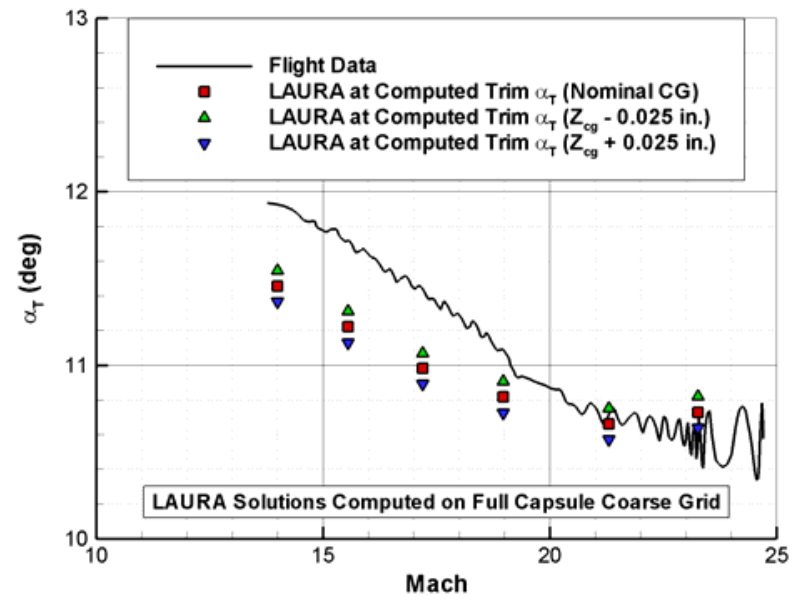

a. Total Angle-of-Attack

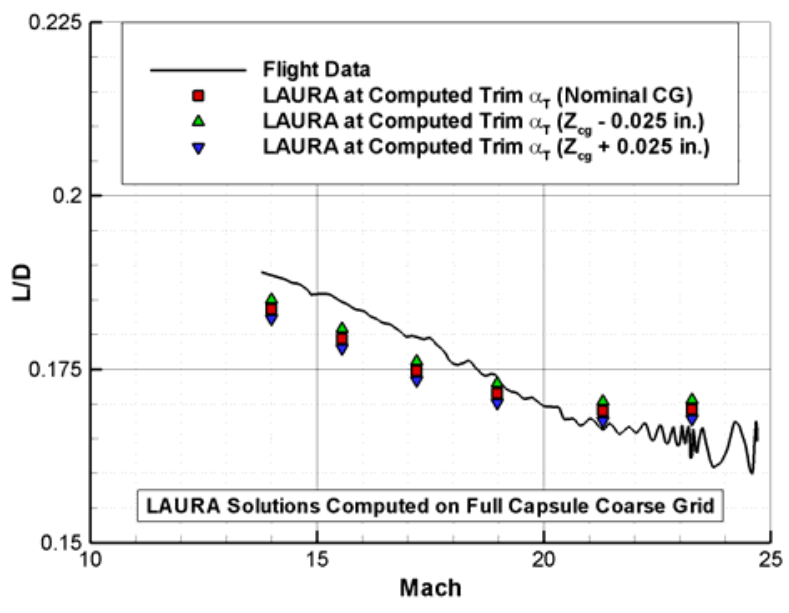

b. Lift-to-Drag Ratio

Figure 14. VL1 Capsule Aerodynamics vs. Mach Number: LAURA Results at Computed Trim Angle-ofAttack Compared to Flight Data, Effects of Radial CG Location 
of the off-nominal $Z_{\mathrm{cg}}$ is to shift the trim angle curve upward for a more offset $C G$, and downward for a $C G$ that is closer to the axis of symmetry. Computed trim angle changes by approximately $+/-0.1 \mathrm{deg}$ and the shapes of the trim $\alpha$ and $\mathrm{L} / \mathrm{D}$ curves remain the same. This amount of change does not explain the full difference between the flight data and LAURA results.

\section{Sensitivity of LAURA Computed Trim Conditions to Atmospheric Density}

The MPF and MER aerodynamics databases were generated for particular reference trajectories (altitude vs. velocity). The hypersonic continuum coefficients were specified as a function of the velocity and total angle-ofattack; density was not explicitly used as an independent variable. Uncertainties in the aerodynamic coefficients are intended to cover in part the possibility that the entry capsule will actually fly an atmospheric density profile that is different from the reference. That is, the effects of atmospheric density profile on aerodynamics are expected to be small and are covered by uncertainties. Reference 2 showed that the MPF aerodynamic coefficients were insensitive to changes in freestream density of $+/-10 \%$ about the nominal value. For VL1, the density profile was not given in Reference 16 for VL1. Instead, the density profile from Reference 17 was used. One question that can be answered is how sensitive are the LAURA VL1 aerodynamics to changes in the atmospheric density.

VL1 flowfield solutions were repeated at the Mach numbers in Table 3 with a factor of two decrease and increase in the atmospheric density on the coarse grid. Of course, if the density profile was different from the one measured, the entry path would be changed. Figure 15 shows the LAURA results with nominal and dispersed density. For Mach numbers below 19, the CFD trim conditions are insensitive to changes in density. At Mach 19 and above, the trim angle changes by as much as 0.2 deg with a factor of two change in density. The Mach 19 and 21.3 velocities $(3800 \mathrm{~m} / \mathrm{s}$ and $4100 \mathrm{~m} / \mathrm{s})$ are within the velocity range where a MPF static instability was predicted. The reason given for the instability was the movement of the sonic line in equilibrium gas chemistry conditions ${ }^{2}$. Perturbations in the atmospheric density that affect the equilibrium state of the post-shock gas may explain the sensitivity at similar velocities for VL1. The Mach 23.3 trim conditions are the most varied, perhaps because the density is very low shortly after atmospheric entry, and any sensitivities to density are exaggerated. A $50 \%$ density reduction at Mach 23.3 results in a density that may be approaching rarefied flow conditions where Direct Simulation Monte Carlo computational methods may be more appropriate.

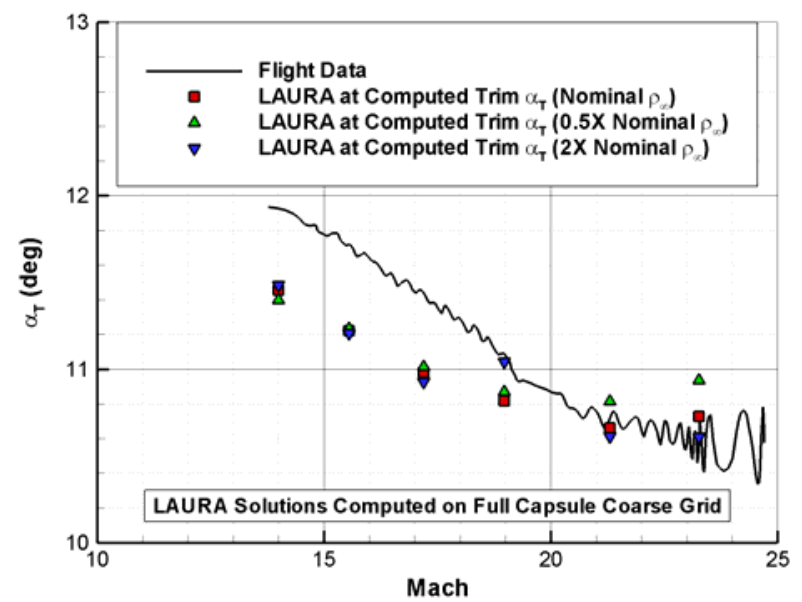

a. Total Angle-of-Attack

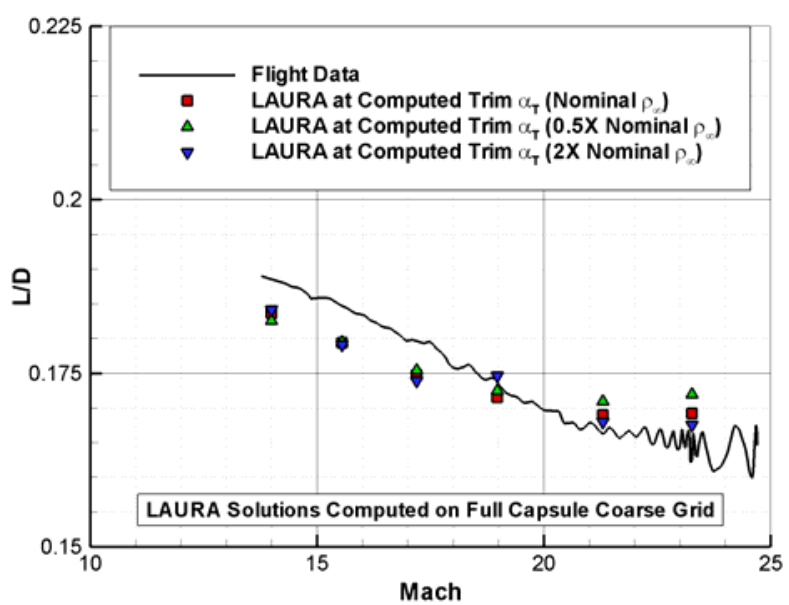

b. Lift-to-Drag Ratio

Figure 15. VL1 Capsule Aerodynamics vs. Mach Number: LAURA Results at Computed Trim Angle-ofAttack Compared to Flight Data, Effects of Atmospheric Density

\section{Sensitivity of LAURA Computed Trim Conditions to Grid Resolution}

The LAURA flight solutions shown so far were all obtained on the coarse grid. The desire is that the aerodynamics for any entry capsule are independent of the grid refinement. Large computational grids can be 
handled with the continued improvements in computational speed and memory. However, grids that allow for reasonable solution turnaround are also needed. In order to determine sensitivity to grid refinement, the VL1 flight solutions were repeated on the fine grid. Figure 16 shows the trim aerodynamics using the coarse and fine grids on the full capsule. The trim angle differences are at most $0.1 \mathrm{deg}$ between the coarse and fine grid solutions (Fig. 16a). This is expected since the aerodynamics are dominated by the forebody pressure, which is well resolved even with coarse grids. Computed trim $\mathrm{C}_{\mathrm{L}}, \mathrm{C}_{\mathrm{D}}$, and $\mathrm{L} / \mathrm{D}$ differ by less than $1 \%$ between the coarse and fine grid solutions.

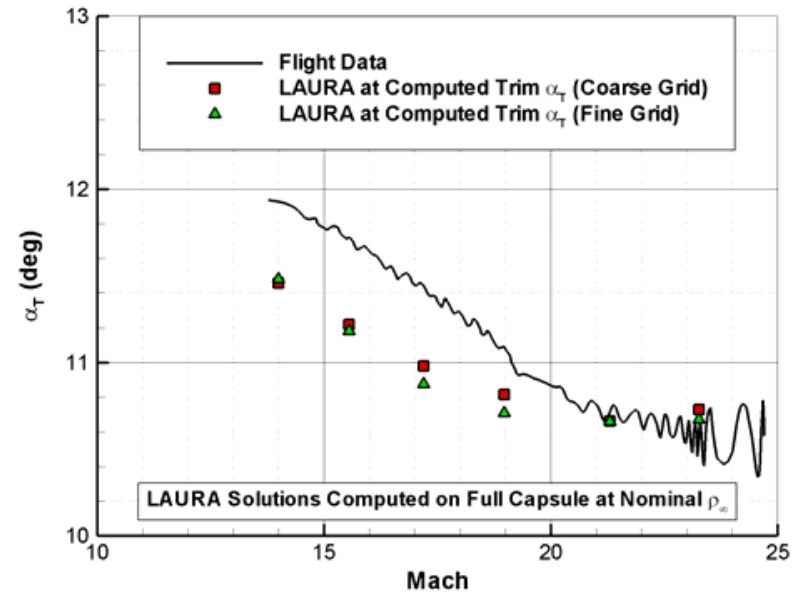

a. Total Angle-of-Attack

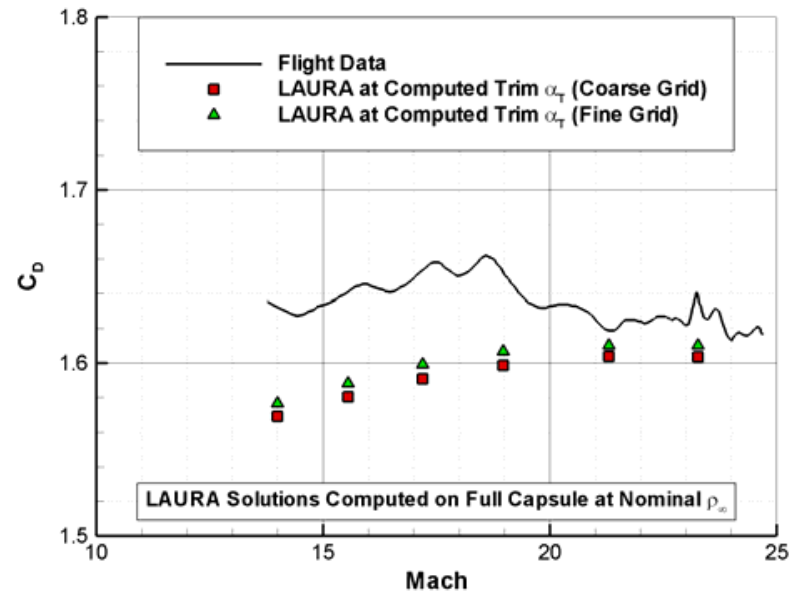

c. Drag Force Coefficient

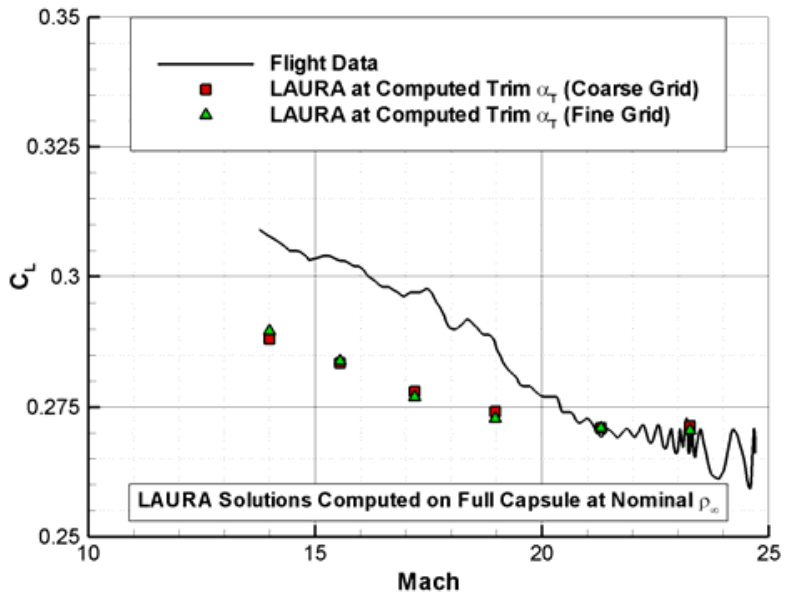

b. Lift Force Coefficient

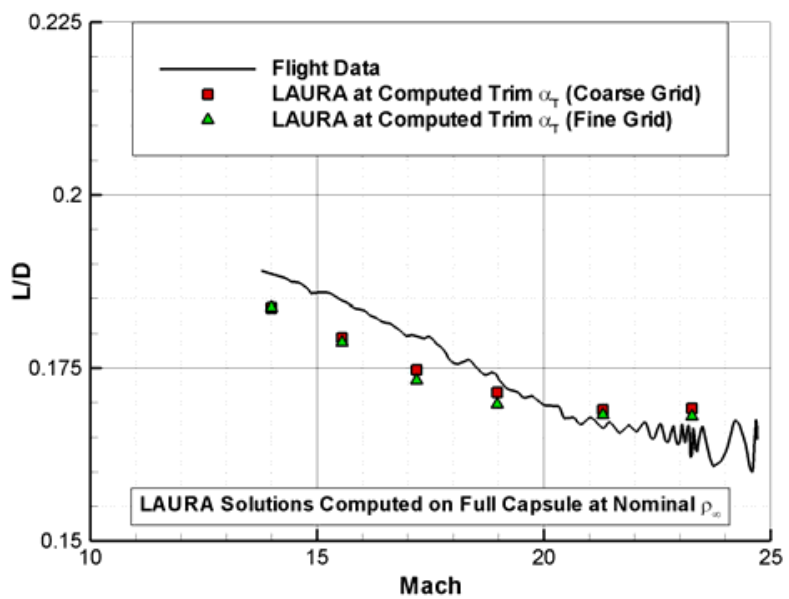

d. Lift-to-Drag Ratio

\section{Figure 16. VL1 Capsule Aerodynamics vs. Mach Number: LAURA Results at Computed Trim Angle-of- Attack Compared to Flight Data, Effects of Grid Resolution}

There are other factors that could have affected the VL1 trim conditions that were not modeled in the LAURA solutions. Reference 1 states that an unsymmetrical effect was observed for VL1 as indicated by unexpectedly high usage of the roll RCS thrusters. Shape changes due to thermal protection system (TPS) material ablation or structural deformation are possible causes of asymmetrical behavior. The LAURA grid assumed a perfectly rigid aeroshell that did not deflect under aerodynamic loads. In reality, the VL1 entry capsule was subjected to decelerations of several Earth g's, which could deflect the structure and change the trim angle from its undeformed value. The pre-flight estimate for the change in trim angle was $0.13 \mathrm{deg}^{9}$. Shape change could have also resulted from TPS material erosion. The maximum VL1 heat flux during entry ${ }^{1}\left(24 \mathrm{~W} / \mathrm{cm}^{2}\right)$ was very mild compared to $\mathrm{MPF}^{27}$, which used the same TPS material. However, small amounts of material removed by ablation could result in asymmetries. 
Overall, CFD methods show good agreement with the VL1 hypersonic flight data, especially at higher Mach numbers. Further work is recommended in the following areas: computational sensitivities to reaction rate and transport property uncertainties; archival search for Viking Lander 1 flight data below Mach 14 for further computational analysis; an estimate of data uncertainties for VL1 hypersonic data; a repeat of the analysis using Viking Lander 2 entry capsule data, if available.

\section{Summary and Conclusions}

Computational fluid dynamics static aerodynamic coefficients (lift force coefficient, drag force coefficient, liftto-drag ratio) using the LAURA code were compared to Viking Lander Capsule wind tunnel data for sting-mounted models (Mach 6 and 10.35) and flight data (Mach 14 to 23.3). Data obtained at NASA Langley Research Center's 20-Inch Mach 6 Air Tunnel and 31-Inch Continuous Flow Hypersonic Tunnel (Mach 10.35) were originally used to give pre-flight estimates of hypersonic trim angle-of-attack $(-11.1 \mathrm{deg})$ and lift-to-drag ratio (0.18). LAURA perfect gas viscous solutions, including sting effects, were obtained at facility conditions across the tested angle-of-attack range. Comparison between LAURA and available ground-based and flight data is needed for better quantification of computational aerodynamic uncertainties for future Mars entry capsules, especially at non-zero angle-of-attack.

As expected, LAURA does well in computing static aerodynamics at hypersonic tunnel conditions in perfect gas facilities. Comparison between LAURA and the ground-based data were made for trim conditions using the flight vehicle center-of-gravity location (0.2209 diameters behind the nose, 0.0133 diameters from the symmetry axis). CFD-based trim angle at tunnel conditions is within 0.31 degrees of the angle derived from Mach 6 data and 0.13 degrees from the Mach 10.35 trim angle. At Mach 6 conditions, the LAURA solutions are within 2 percent of trim lift force coefficient data, 2 percent of trim drag force coefficient, and 4 percent of lift-to-drag ratio. At Mach 10.35 conditions, LAURA trim lift force coefficient is within 5 percent of wind tunnel data, 3 percent for drag force coefficient, and 2 percent for lift-to-drag ratio. LAURA generally predicts a slightly less stable pitching moment coefficient at trim conditions.

On-board accelerometers, pressure ports, and gyros were used to derive angle-of-attack, lift force coefficient, and drag force coefficient for the Viking Lander 1 entry from Mach 23.3 down to Mach 14. LAURA viscous solutions were obtained at flight conditions and included $\mathrm{CO}_{2}-\mathrm{N}_{2}$ finite-rate chemistry effects. The computed trim angle at flight conditions is within 0.5 degrees of the total angle measured from on-board instrumentation. Computed trim aerodynamics are better at higher Mach numbers where the trim angle is closer to the data. The CFD-based trim lift and drag force coefficients are within 7 and 5 percent, respectively, of the flight data. Computed trim lift-to-drag ratio is within 4 percent of the flight data. For a given angle-of-attack, the forebody and full-body solutions give nearly identical lift and drag force coefficients. However, the computed forebody-only trim angle is slightly higher than the full-body angle, which results in small differences in the trim coefficients. For most Mach numbers, changes in atmospheric density are shown to result in negligibly small changes to the aerodynamic coefficients. A +/- 0.25 in. change in the radial center-of-gravity location leads to a $+/-0.1$ deg change in the computed trim angle. The sensitivity of computed aerodynamics to atmospheric density dispersions are small in general for most Mach numbers. The largest effect is seen near Mach 16 to 18, where chemical equilibrium occurs in the shock layer near.

\section{Acknowledgements}

The author would like to thank the following people at NASA Langley Research Center for their contributions in preparing this paper: Bob Blanchard of the Exploration Systems Engineering Branch for discussions about the VL1 flight data; Bill Scallion of the Aerothermodynamics Branch for providing freestream conditions for the NASA Langley Research Center 20-Inch Mach 6 Air Tunnel. 


\section{References}

${ }^{1}$ Ingoldby, R. N., Michel, F. C., Flaherty, T. M., Doryand, M. G., Preston, B., Villyard, K. W., and Steele, R. D., "Entry Data Analysis for Viking Landers 1 and 2 Final Report," NASA CR-159388, Martin Marietta Corporation, Denver Division, Nov. 1976.

${ }^{2}$ Gnoffo, P. A., Braun, R. D., Weilmuenster, K. J., Mitcheltree, R. A., Engelund, W. C., and Powell, R. W.," Prediction and Validation of Mars Pathfinder Hypersonic Aerodynamic Database," Journal of Spacecraft and Rockets, Vol. 36, No. 3, MayJune 1999.

${ }^{3}$ Gnoffo, P. A., Weilmuenster, K. J., Braun, R. D., and Cruz, C. I., "Influence of Sonic-Line Location on Mars Pathfinder Probe Aerothermodynamics," Journal of Spacecraft and Rockets, Vol. 33, No. 2, 1996, pp. 169-177.

${ }^{4}$ Schoenenberger, M., Cheatwood, F. M., and Desai, P. N., "Static Aerodynamics of the Mars Exploration Rover Entry Capsule," AIAA Paper 2005-0056, AIAA Aerospace Sciences Meeting and Exhibit, Reno, NV, Jan. 2005.

5 Schoenenberger, M., Hathaway, W., Yates, L., and Desai, P. N., "Ballistic Range Testing of the Mars Exploration Rover Entry Capsule," AIAA Paper 2005-0055, AIAA Aerospace Sciences Meeting and Exhibit, Reno, NV, Jan. 2005.

6 Lockwood, M. K., Powell, R. W., Graves, C. A., and Carman, G. L., "Entry System Design Considerations for Mars Landers," AAS 01-023, AAS Guidance and Control Conference, Breckenridge, CO, Jan.-Feb. 2001.

7 Murphy, K. J., Horvath, T. J, Erickson, G. E., and Green, J. M., "Supersonic Aerodynamic Characteristics of Proposed Mars '07 Smart Lander Configurations," AIAA Paper 2002-4409, AIAA Atmospheric Flight Mechanics Conference \& Exhibit, Monterey, CA, Aug. 2002.

${ }^{8}$ Bobskill, G. J., Parikh, P. C., Prabhu, R. K., and Tyler, E. D., “Aerodynamic Database Development for Mars Smart Lander Vehicle Configurations," AIAA Paper 2002-4411, AIAA Atmospheric Flight Mechanics, Conference \& Exhibit, Monterey, CA, Aug. 2002.

9 Flaherty, T. “Aerodynamics Data Book, VER-10,” TR-3709014, Martin Marietta Corporation, Denver Division, June 1972.

${ }^{10}$ Blake, W. W., "Experimental Aerodynamic Characteristics of the Viking Entry Vehicle over the Mach Range 1.5 - 10.0," NASA CR-159225, Martin Marietta Corporation, Denver Division, Apr. 1971.

${ }^{11}$ McGhee, R. J., Siemers III, P. M., and Pelt, R. E., "Transonic Aerodynamic Characteristics of the Viking Entry and Lander Configurations,” NASA TM X-2354, NASA Langley Research Center, Sept. 1971.

${ }^{12}$ Blake, W. W., "Transonic Aerodynamic Characteristics and Pressure Distributions on 8 Percent Scale Models of the Viking Lander Capsule, Aeroshell, and Lander Plus Base Cover," NASA CR-159225, Martin Marietta Corporation, Denver Division, Feb. 1971.

${ }^{13}$ Sammonds, R. I., and Kruse, R. L., "Viking Entry Vehicle Aerodynamics at M = 2 In Air And Some Preliminary Test Data For Flight In $\mathrm{CO}_{2}$ At $\mathrm{M}=11$," NASA TN D-7974, Ames Research Center, Moffett Field, CA, June 1975.

${ }^{14}$ Hunt, J. L., Jones, R. A., and Midden, R. E., "Simulation of Real-Gas Effects for Mars Entry", Journal of Spacecraft. Vol. 11, No. 1, Jan. 1974.

${ }^{15}$ Steinberg, S., "Experimental Pitch Damping Derivatives for Candidate Viking Entry Configurations at Mach Numbers from 0.6 through 3.0," TR-3709005, Martin Marietta Corporation, Denver Division, June 1970.

${ }^{16}$ Blanchard, R. C., and Walberg, G. D., "Determination of the Hypersonic-Continuum/Rarefied-Flow Drag Coefficient of the Viking Lander Capsule 1 Aeroshell from Flight Data," NASA TP 1793, Dec. 1980.

${ }^{17}$ Seiff, A., "Atmospheres of Earth, Mars, and Venus, as Defined by Entry Probe Experiments," Journal of Spacecraft, Vol. 28, No. 3, May-June 1991.

${ }^{18}$ Cheatwood, F. M. and Gnoffo, P. A., "User's Manual for the Langley Aerothermodynamic Upwind Algorithm (LAURA)," NASA TM-4674, Apr. 1996.

${ }^{19}$ Papadopoulos, P., Prahbu, D., Olynick, D., Chen, Y. K., and Cheatwood, F. M., "CFD Code Validation and Comparisons for Mars Entry Simulations," AIAA Paper 98-0272, AIAA Aerospace Sciences Meeting \& Exhibit, Reno, NV, Jan. 1998.

${ }^{20}$ Queen, E. M., Cheatwood, F. M., Powell, R. W., Braun, R. D., and Edquist, C. T.: "Mars Polar Lander Aerothermodynamic and Entry Dispersion Analysis," Journal of Spacecraft and Rockets, Vol. 36, No. 3, May-June 1999.

${ }^{21}$ Edquist, K. T, "Afterbody Heating Predictions for a Mars Science Laboratory Entry Vehicle," AIAA Paper 2005-4817, AIAA Thermophysics Conference, Toronto, Ontario, Canada, June 2005.

${ }^{22}$ Edquist, K. T, Wright, M. J., and Allen, G. A. Jr., "Viking Afterbody Heating Computations and Comparisons to Flight Data," AIAA Paper 2006-0386, AIAA Aerospace Sciences Meeting \& Exhibit, Reno, NV, Jan. 2006.

${ }^{23}$ Park, C., Howe, J. T., Jaffe, R. L., and Candler, G. V., "Review of Chemical-Kinetic Problems of Future NASA Missions, II: Mars Entries," Journal of Thermophysics and Heat Transfer, Vol. 8, No.1, Jan.-Mar. 1994.

${ }^{24}$ Roe, P. L., “Approximate Reimann Solvers, Parameter Vectors and Difference Schemes," Journal of Computational Physics, Vol. 43, No. 2, 1981.

${ }^{25}$ Yee, H. C., "On Symmetric and TVD Upwind Schemes," NASA TM-86842, Sept. 1985.

${ }^{26}$ Desai, P. N., Schoenenberger, M., and Cheatwood, F. M., "Mars Exploration Rover Six Degree-of-Freedom Entry Trajectory Analysis," AAS Paper 03-642, AAS/AIAA Astrodynamics Specialists Conference, Big Sky, MT, Aug. 2003.

${ }^{27}$ Milos, F. S., Chen, Y.-K., Congdon, W. M., and Thornton, J. M., "Mars Pathfinder Entry Temperature Data, Aerothermal Heating, and Heatshield Material Response," Journal of Spacecraft and Rockets, Vol. 36, No. 3, May-June 1999. 